\title{
Chemistry of Metals and Alloys
}

\section{A new approach to describe elemental-property parameters}

\author{
Pierre VILLARS $^{1} *$, Jo DAAMS ${ }^{1}$, Yoshihiro SHIKATA ${ }^{2}$, Krishna RAJAN $^{3}$, Shuichi IWATA ${ }^{4}$ \\ ${ }^{1}$ Material Phases Data System (MPDS), CH-6354 Vitznau, Switzerland \\ ${ }^{2}$ Meijo University, Nagoya, Japan \\ ${ }^{3}$ Iowa State University, Ames, IA-50011, U.S.A \\ ${ }^{4}$ The University of Tokyo, Tokyo, Japan \\ * Corresponding author. E-mail: villars.mpds@bluewin.ch
}

Received December 21, 2007; accepted February 17, 2008; available on-line March 31, 2008

The atomic number (AN) of the elements together with their 'periodic number' (PN) were found to form an efficient pair for the discussion of metallurgical and structural problems. The periodic number PN represents a different enumeration of the elements, emphasizing the role of the valence electrons. In contrast to the atomic number, PN depends in details on the underlying Periodic Table of the elements. As a first result we describe the elemental-property parameters 'atomic size $\mathrm{SZ}_{\mathrm{a}}$ ' and 'atomic reactivity $\mathbf{R E}_{\mathrm{a}}$ ', derived from fits to various experimental and theoretical data sets. These two parameters can be approximated as simple functions of AN and PN:

$$
\begin{gathered}
\mathbf{S Z} \mathbf{Z}_{\mathrm{a}}=\mathbf{k}_{\mathrm{SZ}}[\log (\mathbf{A N}+1)]\left[\mathbf{k}_{\mathrm{PN}}-(\log \mathbf{P N})^{3}\right], \\
\mathbf{R E}_{\mathrm{a}}=\mathbf{k}_{\mathrm{RE}}\left\{[\log (\mathbf{A N}+1)]\left[\mathbf{k}_{\mathrm{PN}}-(\log \mathbf{P N})^{3}\right]\right\}^{-1}=\mathbf{k}_{\mathrm{SZ}} \mathbf{k}_{\mathrm{RE}}\left(\mathbf{S Z}_{\mathrm{a}}\right)^{-1},
\end{gathered}
$$

where $\mathrm{k}_{\mathrm{PN}}$ is a scaling factor, and $\mathrm{k}_{\mathrm{Sz}}, \mathrm{k}_{\mathrm{RE}}$ are fit parameters for a fit to experimental data. We argue that all elemental-property parameter patterns are derived from AN and PN. AN and PN represent fundamental elemental-property parameters independent from each other. Any pattern, which shows well-defined functional behavior within each group number GN, as well as within each main quantum number QN, can be included. On the example of compound formers/non-formers in binary, ternary and quaternary chemical systems we demonstrate that a quantitative link exists between material properties and AN, PN (or simple functions of both) of the constituent elements.

Electronegativity / Atomic radii / Chemical elements

\section{Introduction}

Most of the chemical elements are well characterized by quite a number of experimental and theoretical elemental-property parameters, such as the atomic number AN, experimental and theoretical radii, ionization potential, bulk modulus, melting temperature, etc. On plotting these elemental-property parameters versus AN respectively PN, a vast majority of them can be grouped into distinctly different patterns. As examples, three of these patterns are shown in Figs. 1-3.

Elemental-property parameters belonging to the same pattern are qualitatively similar, although they are quantitatively different. The elemental-property parameters used in this work are listed in Tables 1a and 1b. In Table 1a the two fundamental pattern groups and in Table $1 \mathrm{~b}$ four examples of derived pattern groups are given.

Our investigations revealed that the elementalproperty parameters not only characterize the chemical elements themselves but also reflect quantitatively their interaction behavior between each other, which thus opens the possibility to predict physical or chemical properties of multinary systems.

Fundamental elemental-property parameters: Atomic Number AN and Periodic Number PN

Looking closer at the data sets listed in Tables 1a and $1 \mathrm{~b}$ we notice that integer parameter values are only found in the first two patterns (Table 1a). The only comprehensive ones are $\mathrm{AN}$ and $\mathrm{PN}$. The atomic number AN and the periodic number PN (the possibly misleading name for PN was chosen to have a neutral designation for different variants of this parameter) define, in a different way, the position of each element in the Periodic System (or Periodic Table) of the elements. AN is a simple count of the protons of the nucleus, which is equal to the total number of electrons of this element. The periodic number $\mathrm{PN}$ is 


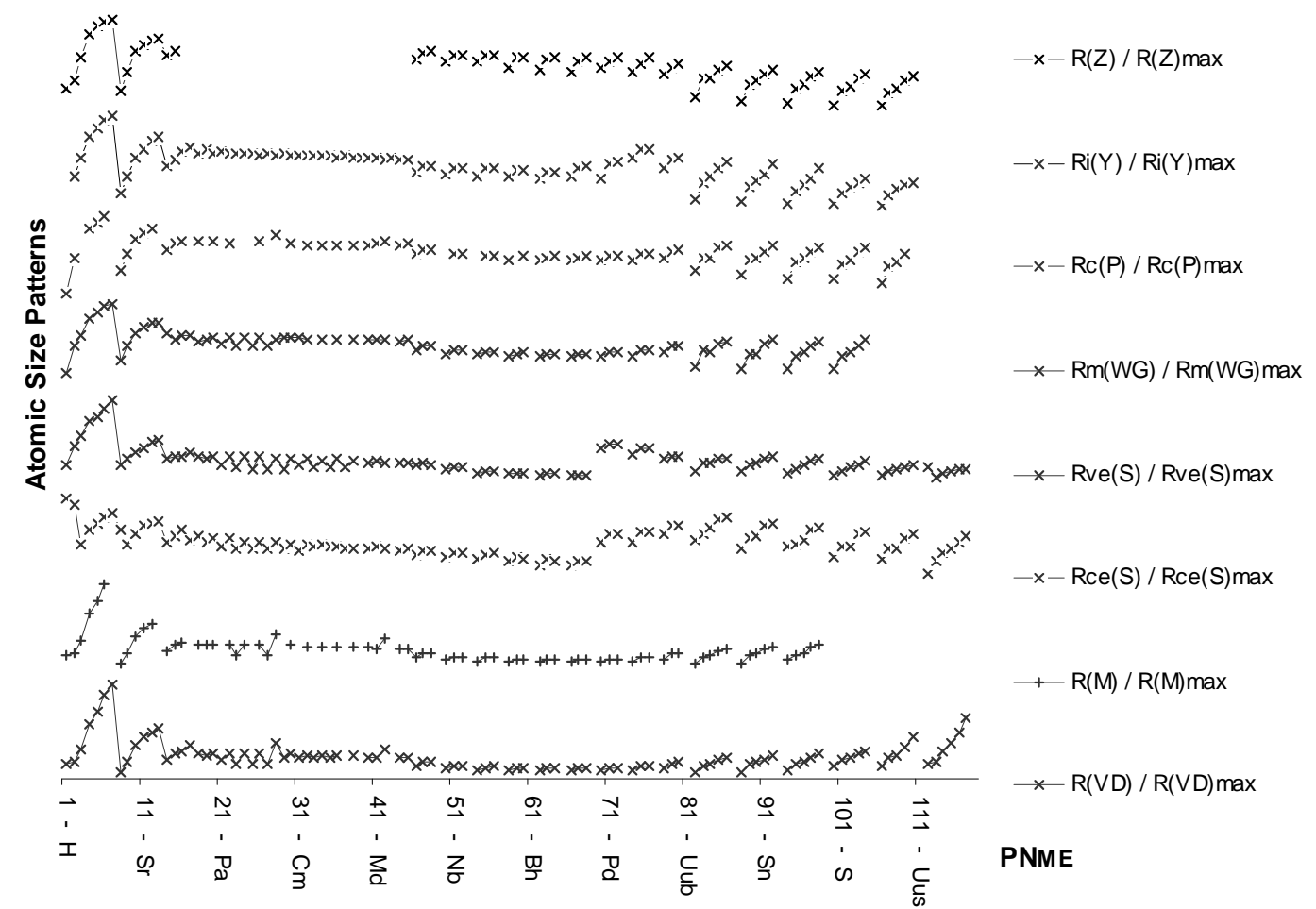

Fig. 1 Eight elemental-property parameters (normalized to their maximum values) belonging to the atomicsize group (Table $1 \mathrm{~b}$ ), plotted versus periodic number $\mathrm{PN}_{\mathrm{ME}}$.

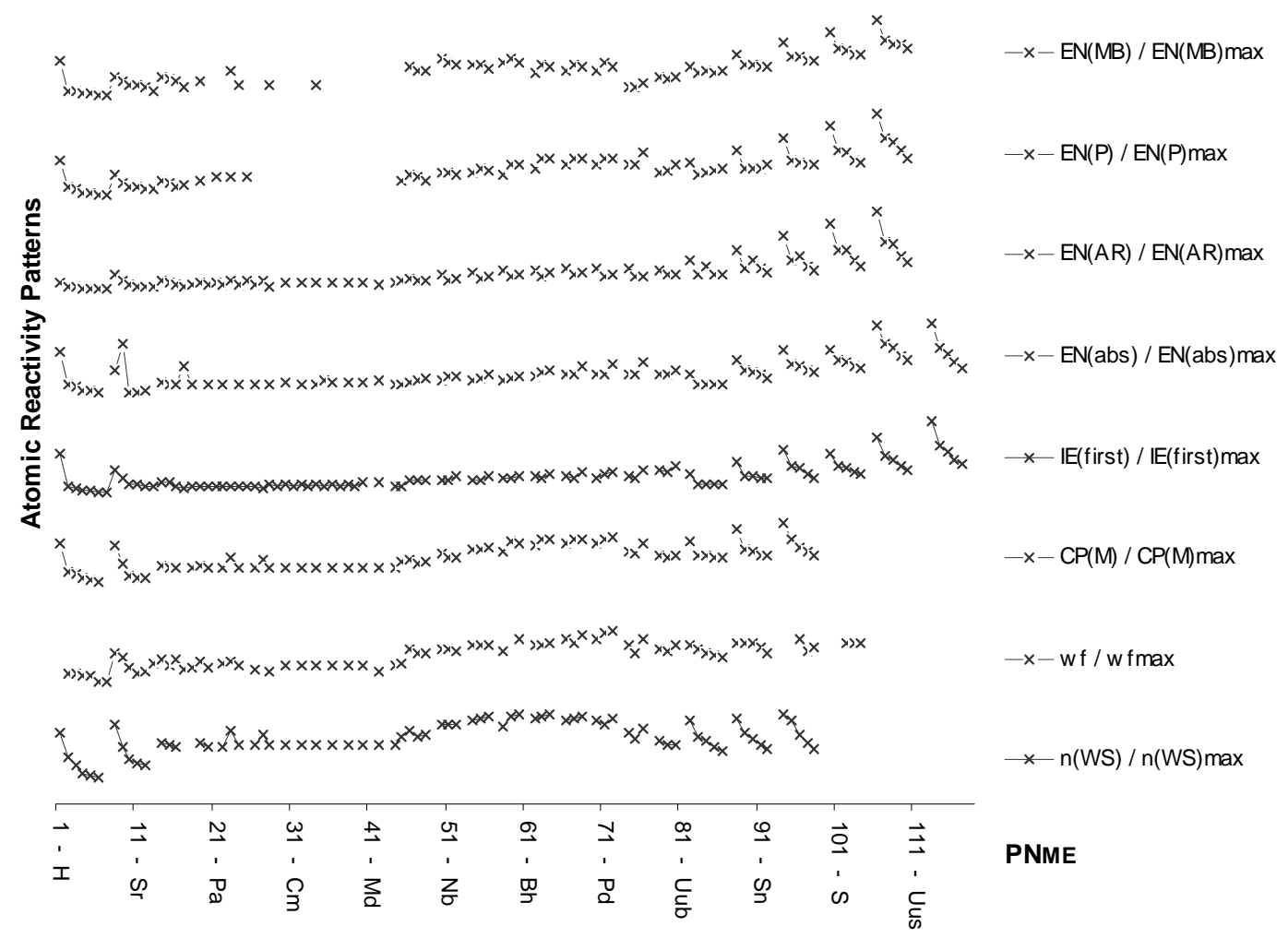

Fig. 2 Eight elemental-property parameters (normalized to their maximum values) belonging to the atomicreactivity group (Table $1 \mathrm{~b}$ ), plotted versus periodic number $\mathrm{PN}_{\mathrm{ME}}$. 
Table 1 (a) The 13 elemental-property parameters considered grouped into the two fundamental groups, the atomic number AN pattern group and the periodic number PN pattern group. (b) The 26 elemental-property parameters considered grouped into the four derived groups, the atomic size pattern group, the atomic reactivity pattern group, the atomic affinity pattern group, and the atomic density pattern group.

(a)

\title{
I) Atomic number pattern group
}

\section{AN: Atomic number}

QN: Main quantum number

AM: Atomic mass [1]

nc(C): Nuclear effective charge according to Clementi [2]

nc(S): Nuclear effective charge according to Slater [3]

$\mathrm{cma}(\mathrm{Mo})$ : Coefficient of mass attenuation for Mo K $\alpha$ [2]

$\mathrm{cma}(\mathrm{Cu})$ : Coefficient of mass attenuation for $\mathrm{Cu} \mathrm{K \alpha}$ [2]

aes: Atomic electron scattering factor [2]

\author{
II) Periodic number pattern group \\ $\mathrm{PN}_{\mathrm{ME}}$ : Periodic number according to Meyer [4] \\ $\mathrm{PN}_{\mathrm{MD}}$ : Periodic number according to Mendeleyev [5] \\ PN(P): Periodic number MN according to Pettifor's sequence [6] \\ VE: Valence electron number \\ GN: Group number
}

(b)

i) Atomic size pattern group

$\mathrm{R}(\mathrm{Z})$ : Pseudo-potential radii according to Zunger [7]

$\mathrm{Ri}(\mathrm{Y})$ : Ionic radii according to Yagoda [2]

$\mathrm{Rc}(\mathrm{P})$ : Covalent radii according to Pauling [2]

$\mathrm{Rm}(\mathrm{WG})$ : Metal radii according to Waber and Gschneidner [8]

Rve(S): Valence electron distance according to Schubert [9]

Rce(S): Core electron distance according to Schubert [9]

$\mathrm{R}(\mathrm{M})$ : Radii according to Miedema (derived from his $\mathrm{V}^{2 / 3}$ compilation) [10]

$\mathrm{R}(\mathrm{VD})$ : Radii according to Villars and Daams (derived from their V compilation) [11]

\section{ii) Atomic reactivity pattern group}

EN(MB): Electronegativity according to Martynov and Batsanov [12]

EN(P): Electronegativity according to Pauling [1]

EN(AR): Electronegativity according to Allred and Rochow [2]

EN(abs): Absolute electronegativity [9]

IE(first): First ionization energy [1]

$\mathrm{CP}(\mathrm{M})$ : Chemical potential according to Miedema [10]

wf: Work function [1]

$\mathrm{n}(\mathrm{WS})$ : $\mathrm{n}$ (Wigner and Seitz) according to Miedema [10]

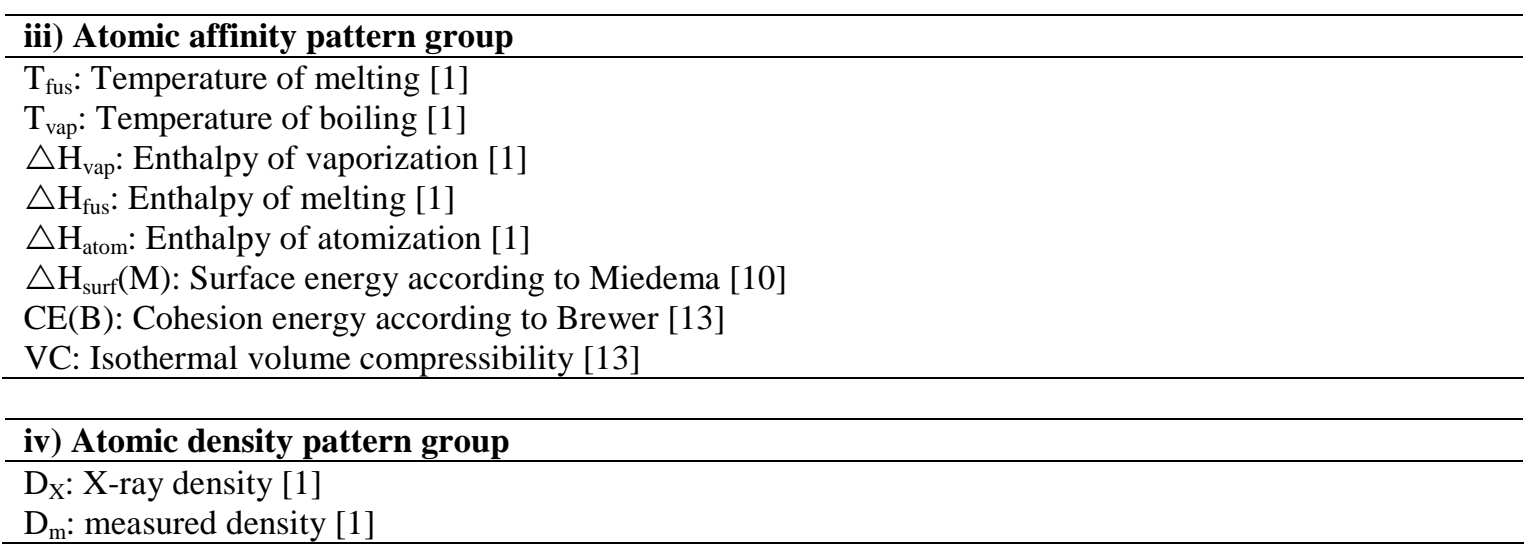




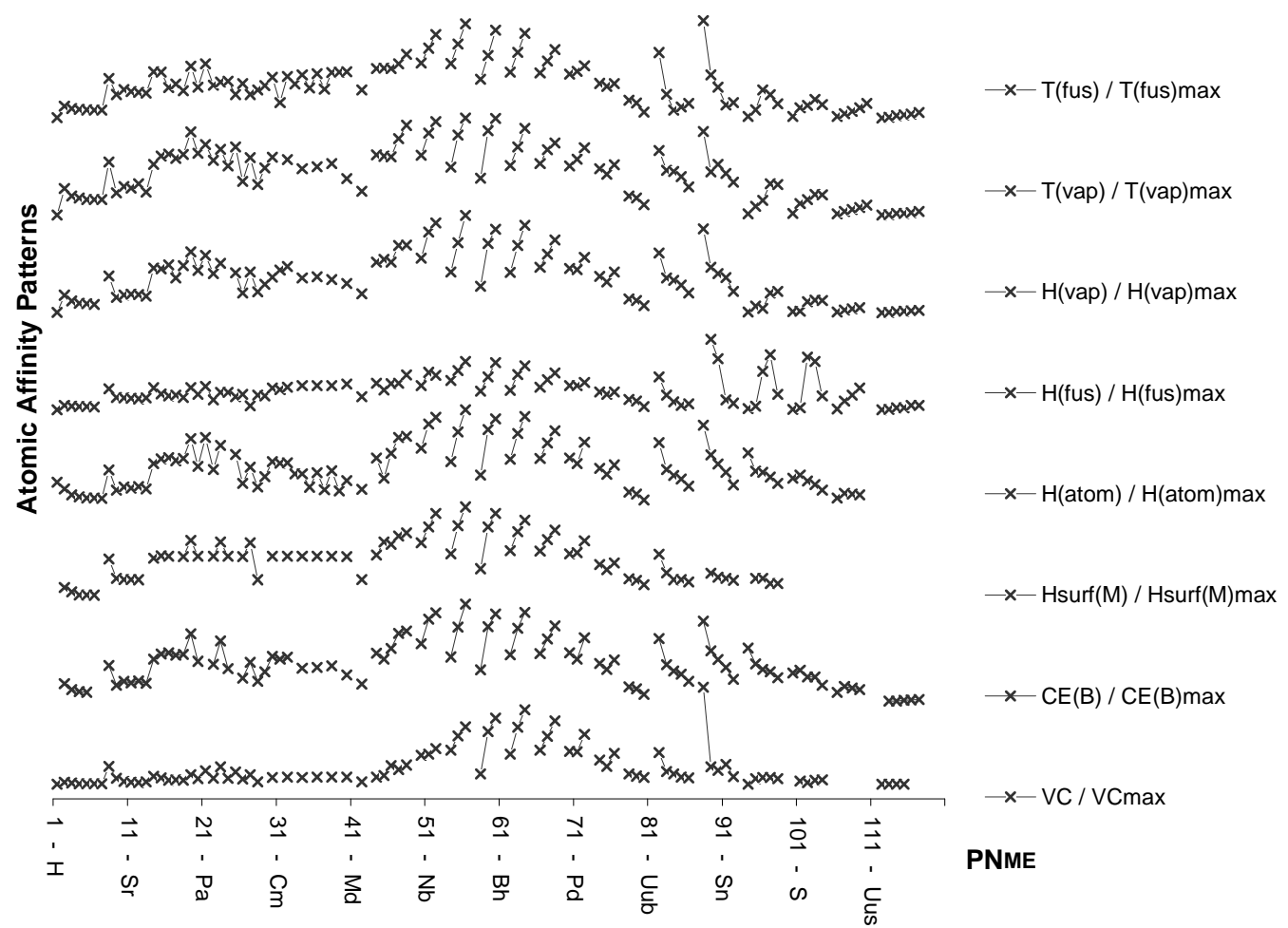

Fig. 3 Eight elemental-property parameters (normalized to their maximum values) belonging to the atomicaffinity group (Table $1 \mathrm{~b}$ ), plotted versus periodic number $\mathrm{PN}_{\mathrm{ME}}$.

the result of a slightly more differentiated enumeration of the elements, since it emphasizes the role of the valence electrons, i.e. it implicitly reflects the construction principle of the Periodic System, which is less obvious from $\mathrm{AN}$. In other words, $\mathrm{AN}$ is the sequence number of the chemical elements within the Periodic Table obtained by counting in first priority within the same main quantum number QN with increasing group number $\mathrm{GN}$, and in second priority with increasing main quantum number QN. AN sequence: $\mathrm{H}, \mathrm{He}(\mathrm{QN}$ 1), $\mathrm{Li}, \mathrm{Be}, \mathrm{B}, \mathrm{C}, \mathrm{N}, \mathrm{O}, \mathrm{F}, \mathrm{Ne}$ (QN 2), Na, Mg, .... Ar (QN 3), K, Ca, ... Kr (QN 4), etc. Smooth functions of AN are obtained, e.g. for the radii of maximum radial charge density or for the energies of innermost electrons, such as $1 \mathrm{~s}, 2 \mathrm{~s}$, but not for outer electrons $4 \mathrm{~s}, 5 \mathrm{~s}, 5 \mathrm{p}$. For most properties the problems begin with QN 4, where the occurrence of the $3 \mathrm{~d}$ electrons leads to irregular valences and to Groups IA, IIA and IB, IIB in Meyer's Periodic Table, where IIA and IIB elements both possess two valence electrons

For the periodic number PN the enumeration of the elements is performed in first priority within the same group number GN with increasing main quantum number QN, and in second priority with increasing group number GN. The familiar group names of the Periodic System of Meyer (Groups IA, IIA, IIIB, IVB, VB, VIB, VIIB, VIIIB (for the Fe, Co and Ni groups), IB, IIB, IIIA, IVA, VA, VIA, VIIA, VIIIA) are replaced by GN 1, 2, .. 18 (18 = maximum number of $\mathrm{s}$, $\mathrm{p}$, and $\mathrm{d}$ electrons, $2+6+10)$. The details, however, depend on the arrangement of the underlying
Periodic Table.

In the representation of Sanderson [14], e.g. the transition elements (including $\mathrm{Cu}, \mathrm{Ag}$ and $\mathrm{Au}$ ) are listed as insert below $\mathrm{Be}, \mathrm{Mg}$ and between $\mathrm{Ca}, \mathrm{Sr}, \mathrm{Ba}$, $\mathrm{Ra}$ and $\mathrm{Zn}, \mathrm{Cd}, \mathrm{Hg}$, in the same way as the rare-earth elements $\mathrm{Ce} . . . \mathrm{Yb}$ and the actinide elements $\mathrm{Th}$...No are inserted below Sc, Y and between La, Ac and Lu, Lr. We mention this kind of Periodic Table because it visualizes the uncertainty in placing the elements $\mathrm{Be}$, $\mathrm{Mg}$, which are found above $\mathrm{Ca}, \mathrm{Sr}, \mathrm{Ba}, \mathrm{Ra}$ in Meyer's Periodic Table [4], but above $\mathrm{Zn}, \mathrm{Cd}, \mathrm{Hg}$ in Mendeleyev's Periodic Table [5]. This rises the question whether the rare-earth elements and above all the actinide elements also should obtain proper group numbers (all the more as the early actinides really behave like transition elements).

A possibly more important question is that about the placement of the hydrogen atom, H. For a discussion of properties of non-metallic compounds a better placement of $\mathrm{H}$ is certainly above fluor, $\mathrm{F}$ (i.e. above the halogen group) as in Mendeleyev's Periodic Table, because the observed valence states of $\mathrm{H}$ are +1 and -1 , in contrast to the elements of Group $1, \mathrm{Li}$, $\mathrm{Na}, . . \mathrm{Fr}$, which can act only as cations.

The first time that a periodic-number-like scale was used as elemental-property parameter [15,16], it was employed as a kind of phenomenological scale. In a more recent work [17] several variants of PN were used with the aim to separate compound-forming systems from non-formers in plots of 2D- and 3Delemental-property parameter expressions (also called features). Some variants were found to be of similar 
efficiency. Still another variant was recently successfully applied in order to separate different atomic-environment types (AET) of the constituents in equiatomic binary compounds [18]. In most of the above cases the periodic-number-like scale or PN was then called 'Mendeleev number'.

In the following, we restrict our considerations to two basic variants, the "physicist's version" based on the Periodic Table of L. Meyer [4] and the "chemist's version" based on the Periodic Table of D.I. Mendeleyev [5] (the designation is not a judgment). The shift of $\mathrm{H}$ from $\left(\mathrm{AN}, \mathrm{PN}_{\mathrm{ME}}\right)=(1,1)$ to $\left(\mathrm{AN}, \mathrm{PN}_{\mathrm{MD}}\right)=$ $(1,105)$ is the reason why only the elements with PN $>105$ keep the same (AN, PN) pair numbers in both systems, i.e. $\mathrm{PN}($ Meyer $) \neq \mathrm{PN}($ Mendeleyev) for $\mathrm{H}$ and all elements with GNs 1-16.

In order to distinguish between the two versions we name the particular periodic number PN derived from Meyer's Periodic Table the Meyer number $\mathrm{PN}_{\mathrm{ME}}$, and that derived from Mendeleyev's Periodic Table the Mendeleyev number $\mathrm{PN}_{\mathrm{MD}}$.

In Figs. 4, 5 we show the step-like functions $\mathrm{PN}_{\mathrm{ME}} /\left(\mathrm{PN}_{\mathrm{ME}}\right)_{\max }$ and $\mathrm{GN} / \mathrm{GN}_{\max }$ versus $\mathrm{AN}$, and the reversed version $\mathrm{AN} / \mathrm{AN}_{\max }$ and $\mathrm{QN} / \mathrm{QN}_{\max }$ versus $\mathrm{PN}_{\mathrm{ME}}$, where $\mathrm{AN}_{\max }=\mathrm{PN}_{\max }=118, \mathrm{GN}_{\max }=18$,
$\mathrm{QN}_{\max }=7$ for the elements known up to now together with some predicted ones.

Derived elemental-property parameters: Atomic Size $\mathrm{SZ}_{\mathrm{a}}$ and its reciprocal, the Atomic Reactivity $R_{\mathrm{a}}$, as functions of $\mathrm{AN}$ and $\mathrm{PN}$

In Figs. 1, 2 eight different data sets are plotted as functions of $\mathrm{PN}_{\mathrm{ME}}$. Within each pattern group the eight data sets show rather similar functional behavior (patterns) although they differ quantitatively from each other. Each pattern group shows well-defined functional behavior within each group number GN, as well as within each main quantum number QN.

Encouraged by this experience and after observing by chance that in a first approximation $\operatorname{Ri}($ Yagoda) $\approx$ (PN - GN), we started studying functions like (PN / $\left.\mathrm{PN}_{\max }\right)^{\mathrm{x}},\left(\log \mathrm{PN} / \log \mathrm{PN}_{\max }\right)^{\mathrm{x}},\{[\mathrm{k}-\mathrm{PN}] /[\mathrm{k}-$ $\left.\left.\mathrm{PN}_{\max }\right]\right\}^{\mathrm{x}},\left\{[\mathrm{k}-(\log \mathrm{PN})] /\left[\mathrm{k}-\left(\log \mathrm{PN}_{\max }\right)\right]\right\}^{\mathrm{x}}, \ldots$ versus $A N$ and the analogous functions of $A N$ versus $\mathrm{PN}, \mathrm{x}= \pm 1, \pm 2, \ldots$ and $\mathrm{k}=\left(\mathrm{PN}_{\max }\right)^{\mathrm{x}}$ or $\left(\mathrm{AN}_{\max }\right)^{\mathrm{x}}$, respectively $\left(\log \mathrm{PN}_{\max }\right)^{\mathrm{x}}$ or $\left(\log \mathrm{AN}_{\max }\right)^{\mathrm{x}}$, with the aim to reproduce elemental-property parameters by a combination of such simple functions of AN and PN.

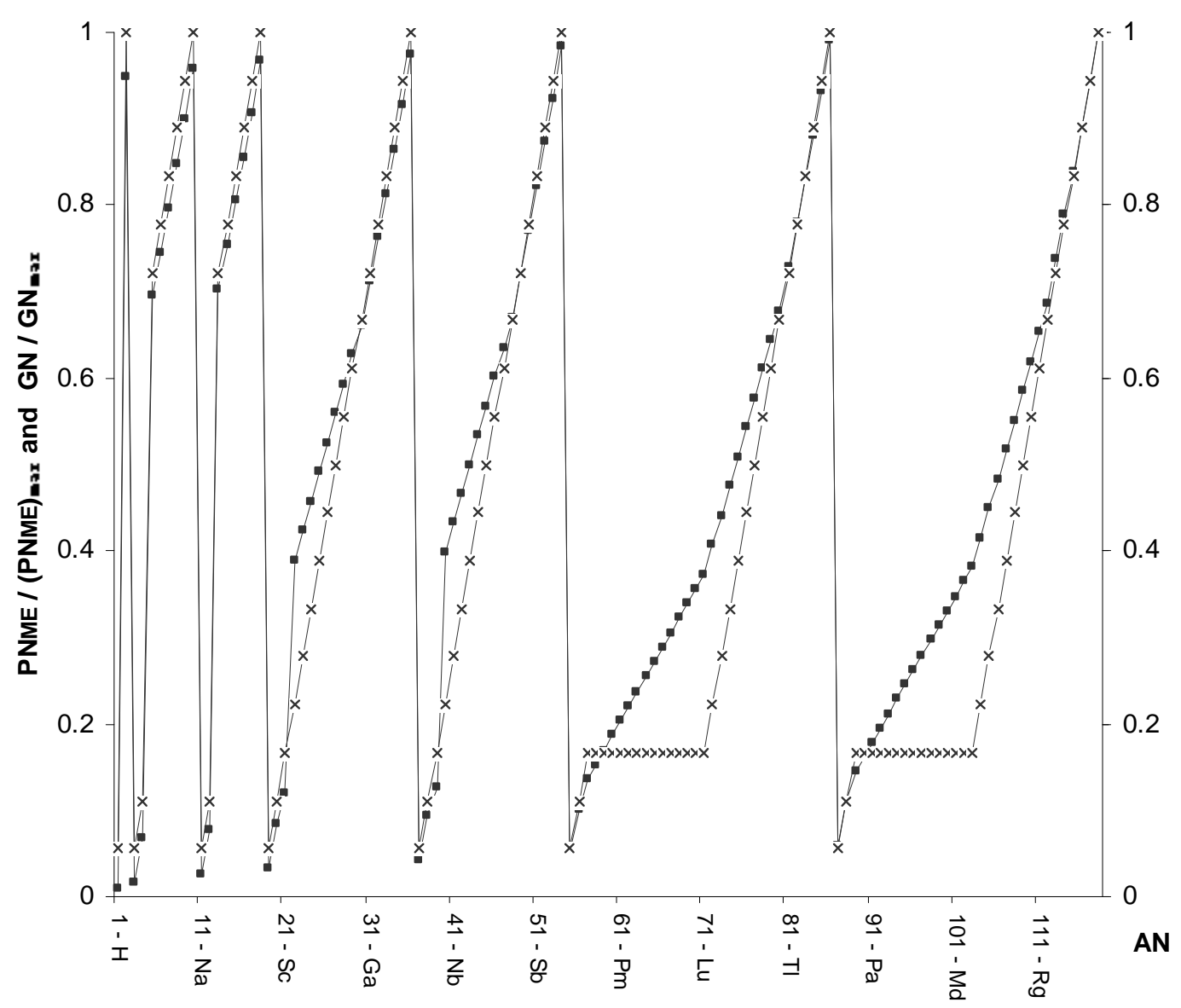

Fig. 4 Periodic number $\mathrm{PN}_{\mathrm{ME}} /\left(\mathrm{PN}_{\mathrm{ME}}\right)_{\max }$ and group number $\mathrm{GN} / \mathrm{GN}_{\max }$ versus atomic number $\mathrm{AN}$; - $\mathrm{PN}_{\mathrm{ME}} /\left(\mathrm{PN}_{\mathrm{ME}}\right)_{\max }, \times \mathrm{GN} / \mathrm{GN}_{\max }$. 


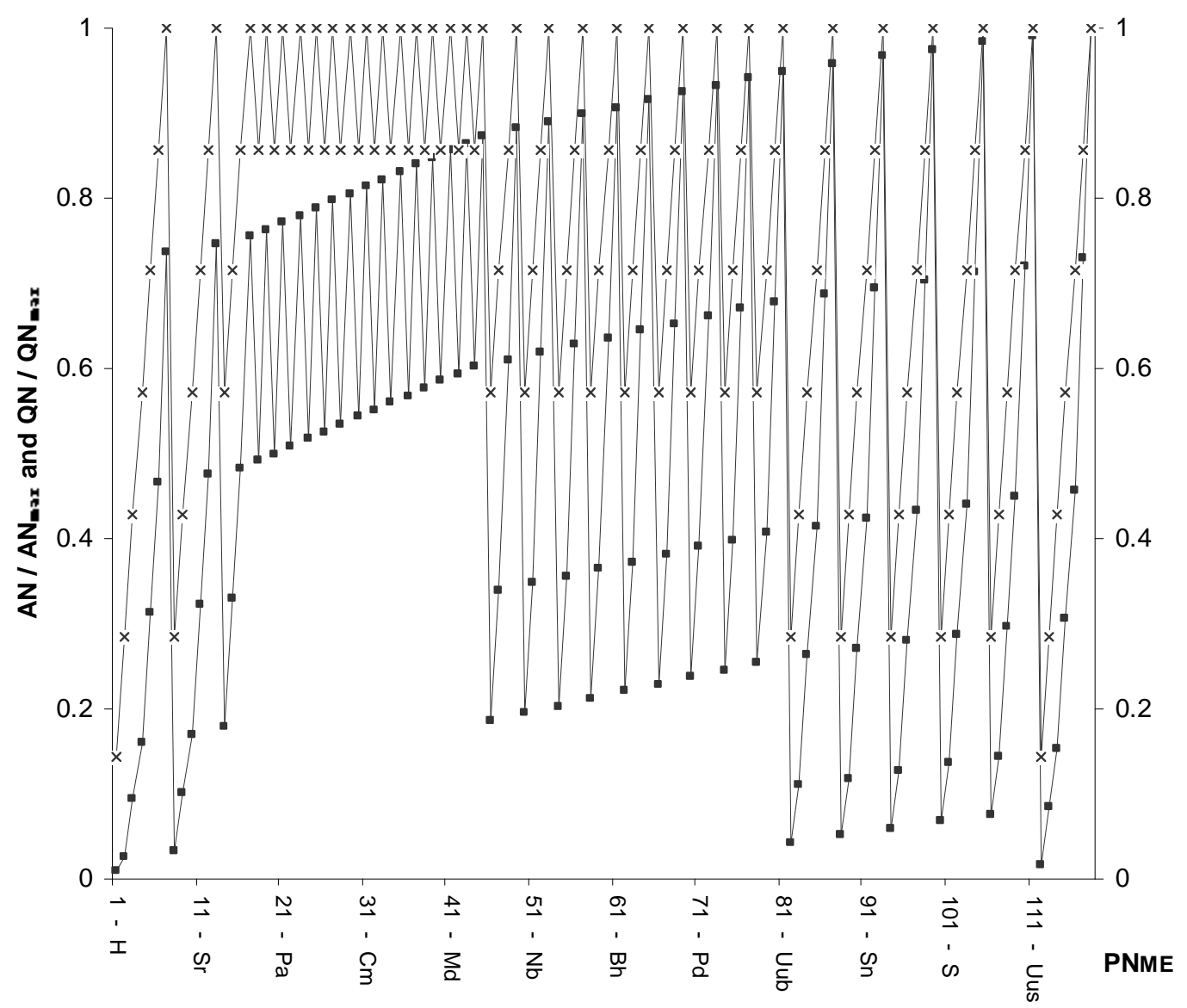

Fig. 5 Atomic number $\mathrm{AN} / \mathrm{AN}_{\max }$ and main quantum number $\mathrm{QN} / \mathrm{QN}_{\max }$ versus periodic number $\mathrm{PN}_{\mathrm{ME}}$;

- $\mathrm{AN} / \mathrm{AN}_{\max }, \times \mathrm{QN} / \mathrm{QN}_{\max }$.

A systematic trial and error approach led us finally to the following approximations for the atomic size $\mathrm{SZ}_{\mathrm{a}}$ and the atomic reactivity $\mathrm{RE}_{\mathrm{a}}$ :

$$
\begin{aligned}
& \mathrm{SZ}_{\mathrm{a}}=\mathrm{k}_{\mathrm{SZ}}[\log (\mathrm{AN}+1)]\left[\mathrm{k}_{\mathrm{PN}}-(\log \mathrm{PN})^{3}\right](1) \\
& \mathrm{RE}_{\mathrm{a}}=\mathrm{k}_{\mathrm{RE}}\left\{[ \operatorname { l o g } ( \mathrm { AN } + 1 ) ] \left[\mathrm{k}_{\mathrm{PN}}-\right.\right. \\
& \left.\left.(\log \mathrm{PN})^{3}\right]\right\}^{-1}=\mathrm{k}_{\mathrm{RE}} \mathrm{k}_{\mathrm{SZ}}\left(\mathrm{SZ}_{\mathrm{a}}\right)^{-1}
\end{aligned}
$$

The scaling number $\mathrm{k}_{\mathrm{PN}}$ turned out to be defined by

$$
\mathrm{k}_{\mathrm{PN}}=\log (\mathrm{AN}+1)_{\max }+\left(\log \mathrm{PN}_{\max }\right)^{3}=10.9695,
$$

for $\mathrm{PN}_{\mathrm{ME}}$ and $\mathrm{PN}_{\mathrm{MD}}$.

The factors $k_{S Z}$ and $k_{R E}$ are fitting parameters for an adaptation to experimental or theoretical data sets. In Tables $2 \mathrm{a}$ and $2 \mathrm{~b}$ we avoided this fitting by introducing normalized parameters:

$$
\mathrm{SZ}_{\mathrm{a}} /\left(\mathrm{SZ}_{\mathrm{a}}\right)_{\max }=\mathrm{SZ}_{\mathrm{a}} / \mathrm{SZ}_{\mathrm{a}}(\mathrm{Fr}),
$$
here

$$
\mathrm{SZ}_{\mathrm{aME}}(\mathrm{Fr})=\mathrm{k}_{\mathrm{SZME}}(\log 88)\left[\mathrm{k}_{\mathrm{PN}}-(\log 7)^{3}\right]=
$$$$
=20.1564 \mathrm{k}_{\mathrm{SZME}}
$$

for the Meyer Table, and

$\mathrm{SZ}_{\mathrm{aMD}}(\mathrm{Fr})=\mathrm{k}_{\mathrm{SZMD}}(\log 88)\left[\mathrm{k}_{\mathrm{PN}}-(\log 6)^{3}\right]=$

$$
=20.4138 \mathrm{k}_{\mathrm{SZMD}}
$$

for the Mendeleyev Table.

For the normalization of $\mathrm{RE}_{\mathrm{aME}}$ and $\mathrm{RE}_{\mathrm{aMD}}$ we did not choose $\mathrm{RE}_{\mathrm{aME}}(\mathrm{He})$ and $\mathrm{RE}_{\mathrm{aMD}}(\mathrm{He})$ respectively, which appeared to be too high, but we chose

$$
\begin{aligned}
& \mathrm{RE}_{\mathrm{aME}}(\mathrm{Ne})=\mathrm{RE}_{\mathrm{aMD}}(\mathrm{Ne}) \\
& \quad \mathrm{RE}_{\mathrm{a}} / \mathrm{RE}_{\mathrm{a}}(\mathrm{Ne})=\mathrm{SZ}_{\mathrm{a}}(\mathrm{Ne}) / \mathrm{SZ}_{\mathrm{a}}=(\log 11)\left[\mathrm{k}_{\mathrm{PN}}-\right. \\
& \\
& \left.\quad(\log 113)^{3}\right] /[\log (\mathrm{AN}+1)]\left[\mathrm{k}_{\mathrm{PN}}-(\log \mathrm{PN})^{3}\right] \\
& \text { or } \quad \\
& \quad \mathrm{RE}_{\mathrm{aME}} / \mathrm{RE}_{\mathrm{aME}}(\mathrm{Ne})=2.4114\{[\log (\mathrm{AN}+1)] \\
& \quad\left[\mathrm{k}_{\mathrm{PN}}-\left(\log \mathrm{PN} \mathrm{ME}^{3}\right]\right\}^{-1}
\end{aligned}
$$

for Meyer's Periodic Table. The analogous equation based on Mendeleyev's Periodic Table differs only in the $\log \mathrm{PN}$ term:

$$
\mathrm{RE}_{\mathrm{aMD}} / \mathrm{RE}_{\mathrm{aMD}}(\mathrm{Ne})=2.4114\{[\log (\mathrm{AN}+1)]
$$$$
\left.\left[\mathrm{k}_{\mathrm{PN}}-\left(\log \mathrm{PN}_{\mathrm{MD}}\right)^{3}\right]\right\}^{-1} \text {. }
$$

Table 2a gives $\mathrm{AN}, \mathrm{PN}_{\mathrm{ME}}, \mathrm{SZ}_{\mathrm{aME}} /\left(\mathrm{SZ}_{\mathrm{aME}}\right)_{\max }=$ $\mathrm{SZ}_{\mathrm{aME}} / \mathrm{SZ}_{\mathrm{aME}}(\mathrm{Fr})$, and $\mathrm{RE}_{\mathrm{aME}} / \mathrm{RE}_{\mathrm{aME}}(\mathrm{Ne})$ in Meyer's Periodic Table, while in Table $2 b$ the corresponding values $\mathrm{AN}, \mathrm{PN}_{\mathrm{MD}}, \mathrm{SZ}_{\mathrm{aMD}} /\left(\mathrm{SZ}_{\mathrm{aMD}}\right)_{\max }=$ $\mathrm{SZ}_{\mathrm{aMD}} / \mathrm{SZ}_{\mathrm{aMD}}(\mathrm{Fr})$, and $\mathrm{RE}_{\mathrm{aMD}} / \mathrm{RE}_{\mathrm{aMD}}(\mathrm{Ne})$ are listed according to Mendeleyev's Periodic Table. Figs. 6 and 7 display $\mathrm{SZ}_{\mathrm{aME}} /\left(\mathrm{SZ}_{\mathrm{aME}}\right)_{\max }$ and $\mathrm{RE}_{\mathrm{aME}} / \mathrm{RE}_{\mathrm{aME}}(\mathrm{Ne})$ as function of $\mathrm{PN}_{\mathrm{ME}}$ and $\mathrm{AN}$, respectively. As a consequence of our normalization with $(\mathrm{Ne})$ instead of $(\mathrm{He})$ the values for $\mathrm{RE}_{\mathrm{aME}}(\mathrm{Ne}) / \mathrm{RE}_{\mathrm{aME}}(\mathrm{He})\left(\mathrm{RE}_{\mathrm{aMD}}\right.$ $\left.(\mathrm{Ne}) / \mathrm{RE}_{\mathrm{aMD}}(\mathrm{He})\right)=2.13768$. In the Figs. 6, 7, 9, 11, where this value is used, we set it to 1.2 for representational reasons. 
Table 2a Atomic number $\mathrm{AN}$, periodic number $\mathrm{PN}_{\mathrm{ME}}$, atomic size $\mathrm{SZ}_{\mathrm{aME}} /\left(\mathrm{SZ}_{\mathrm{aME}}\right)_{\max }$ and atomic reactivity $\mathrm{RE}_{\mathrm{aME}} /\left(\mathrm{RE}_{\mathrm{aME}}\right)_{\max }$ using Meyer's Periodic System.

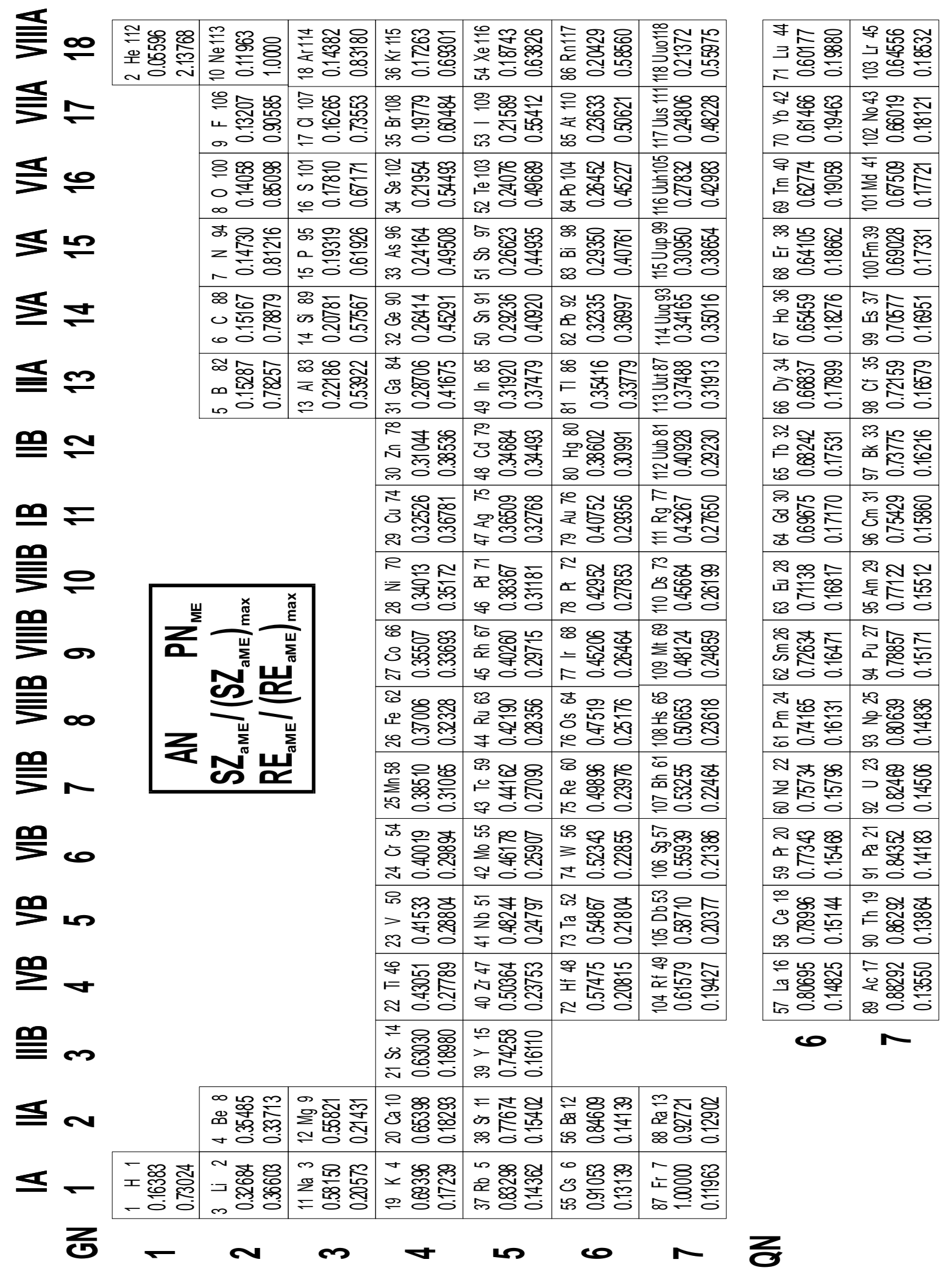


Table 2b Atomic number $\mathrm{AN}$, periodic number $\mathrm{PN}_{\mathrm{MD}}$, atomic size $\mathrm{SZ}_{\mathrm{aMD}} /\left(\mathrm{SZ}_{\mathrm{aMD}}\right)_{\max }$ and atomic reactivity $\mathrm{RE}_{\mathrm{aMD}} /$ $\left(\mathrm{RE}_{\mathrm{aMD}}\right)_{\max }$ using Mendeleyev's Periodic System.

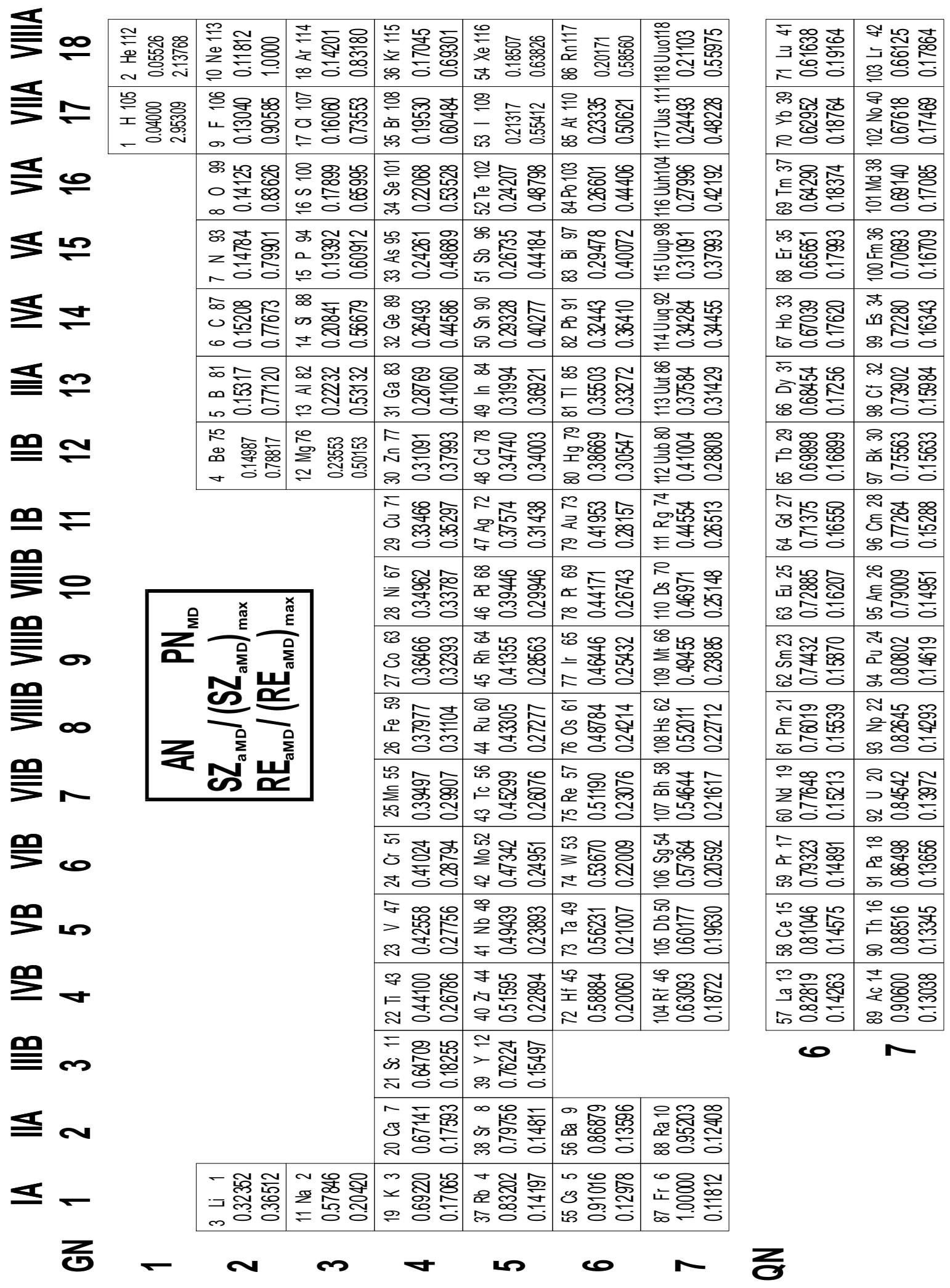


Table 2c Atomic number AN, periodic number $\mathrm{PN}_{\mathrm{ME}}$ and diagonal number $\mathrm{DN}_{\mathrm{ME}}$ in Meyer's Periodic System.

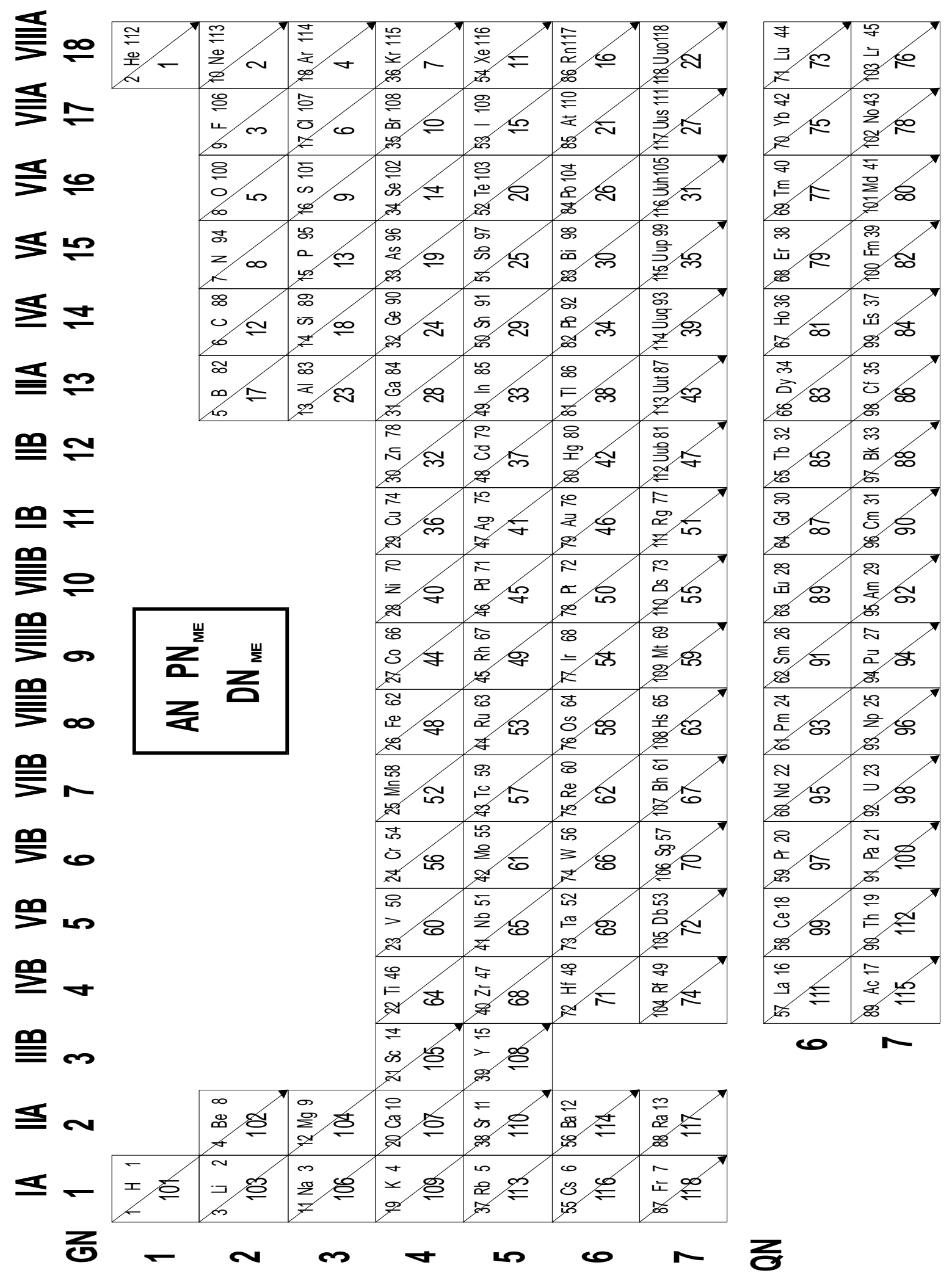




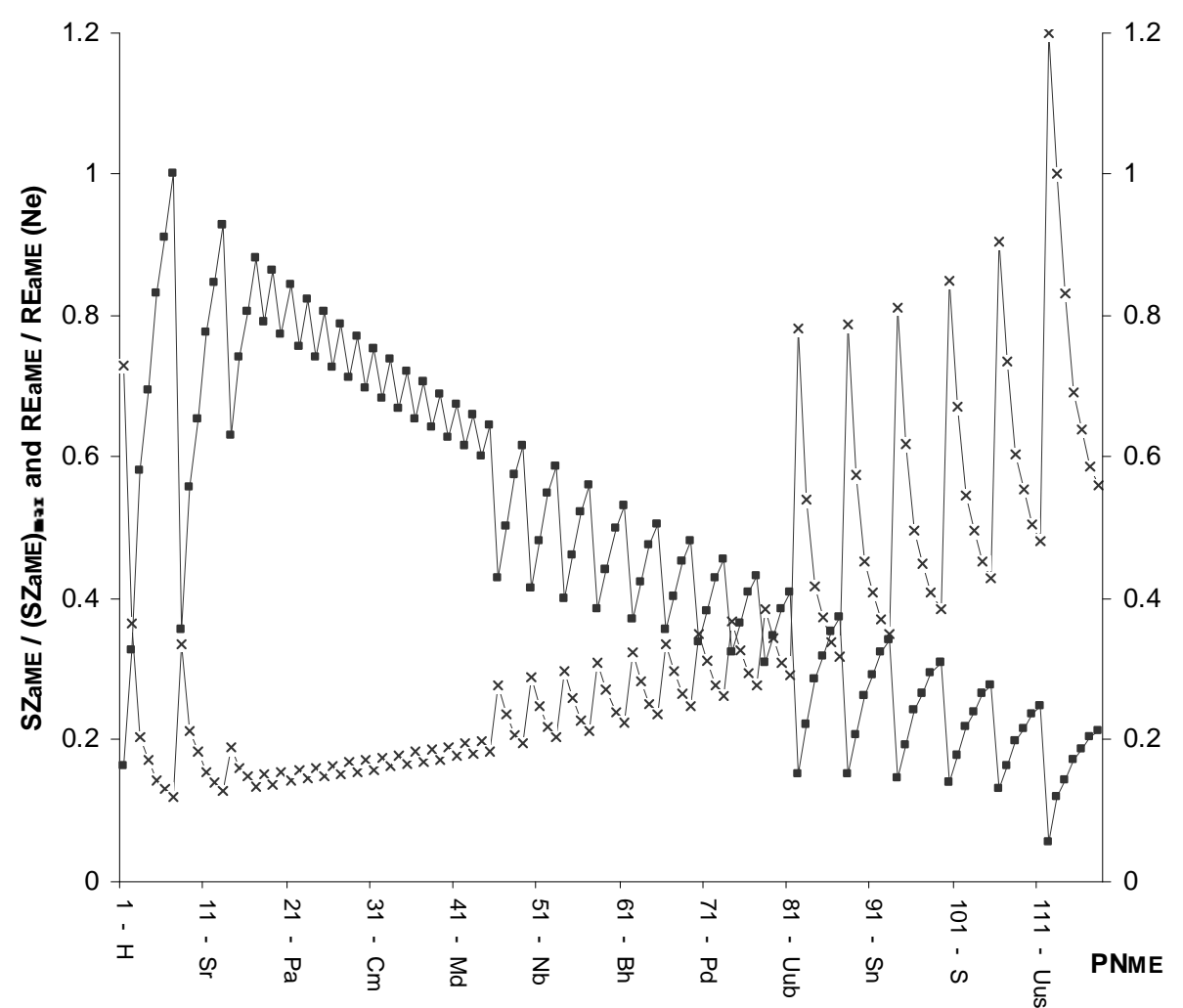

Fig. 6 Atomic size $S Z_{a M E}$ and atomic reactivity $\mathrm{RE}_{\mathrm{aME}}$ (normalized to $\left(\mathrm{SZ}_{\mathrm{aME}}\right)_{\max }$ and $\mathrm{RE} \mathrm{aME}_{\mathrm{a}}(\mathrm{Ne})$ ) versus periodic number $\mathrm{PN}_{\mathrm{ME}}$; $\mathrm{SZ}_{\mathrm{aME}} /\left(\mathrm{SZ}_{\mathrm{aME}}\right)_{\max }, \times \mathrm{RE}_{\mathrm{aME}} / \mathrm{RE}_{\mathrm{aME}}(\mathrm{Ne})$.

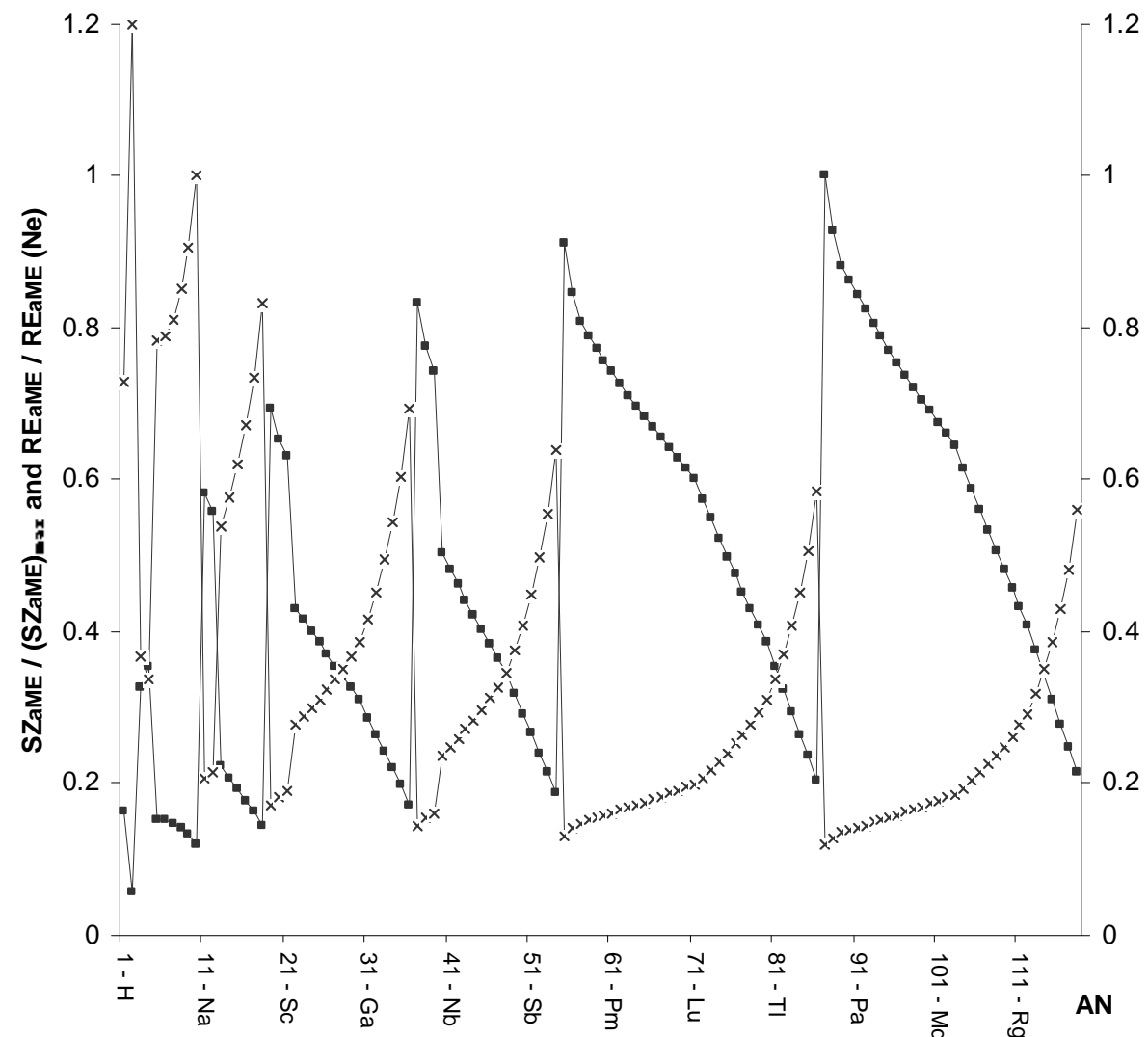

Fig. 7 Atomic size $\mathrm{SZ}_{\mathrm{aME}}$ and atomic reactivity $\mathrm{RE}_{\mathrm{aME}}$ (normalized to $\left(\mathrm{SZ}_{\mathrm{aME}}\right)_{\max }$ and $\mathrm{RE} \mathrm{aME}_{\mathrm{a}}(\mathrm{Ne})$ ) versus atomic number $\mathrm{AN}$; $\mathrm{SZ}_{\mathrm{aME}} /\left(\mathrm{SZ}_{\mathrm{aME}}\right)_{\max }, \times \mathrm{RE}_{\mathrm{aME}} / \mathrm{RE}_{\mathrm{aME}}(\mathrm{Ne})$. 
In Fig. 8 we compare the atomic size $S Z_{\mathrm{aME}}$ and $\mathrm{SZ}_{\mathrm{aMD}}$ (normalized to $\left.\left(\mathrm{SZ}_{\mathrm{aME}}\right)_{\max }=\left(\mathrm{SZ}_{\mathrm{aMD}}\right)_{\max }\right)$ versus atomic number $\mathrm{AN}$. For the calculation of $\mathrm{SZ} \mathrm{aME}_{\mathrm{a}}$ we used the periodic number $\mathrm{PN}_{\mathrm{ME}}$ of Meyer's Periodic Table, and for the calculation of $\mathrm{SZ}_{\mathrm{amD}}$ we used the corresponding periodic number $\mathrm{PN}_{\mathrm{MD}}$ of Mendeleyev's Periodic Table. Fig. 9 gives the analog for the atomic reactivity $R_{a M E}$ and $R E_{a M D}$. It visualizes clearly that, with the exception of those of $\mathrm{H}, \mathrm{Be}$ and $\mathrm{Mg}$, the values are just slightly different (see also Tables $2 \mathrm{a}$ and $2 \mathrm{~b}$ ).

Figs. 10 and 11 compare $\mathrm{R}(\mathrm{Z}) / \mathrm{R}(\mathrm{Z})_{\max }, \mathrm{Ri}(\mathrm{Y}) /$ $\mathrm{Ri}(\mathrm{Y})_{\max }$ and $\mathrm{SZ}_{\mathrm{aME}} /\left(\mathrm{SZ}_{\mathrm{aME}}\right)_{\max }$, respectively $\mathrm{EN}(\mathrm{AR})$ / $\mathrm{EN}(\mathrm{AR})_{\max }, \mathrm{EN}(\mathrm{MB}) / \mathrm{EN}(\mathrm{MB})_{\max }$ and $\mathrm{RE}_{\mathrm{aME}}$ / $\mathrm{RE}_{\mathrm{aME}}(\mathrm{Ne})$ as function of $\mathrm{PN}_{\mathrm{ME}} \cdot \mathrm{R}(\mathrm{Z}), \mathrm{Ri}(\mathrm{Y})$, $\mathrm{EN}(\mathrm{AR})$, and $\mathrm{EN}(\mathrm{MB})$ showed so far to be the most effective ones among the derived elemental-property parameters for separating compound formers from non-formers in multinary systems [17], as well as in structure maps [18]. $\mathrm{SZ}_{\mathrm{aME}}\left(\mathrm{SZ}_{\mathrm{aMD}}\right)$ and $\mathrm{RE}_{\mathrm{aME}}$ $\left(\mathrm{RE}_{\mathrm{aMD}}\right)$ fit very well in the general trend of the pattern behaviors shown in Figs. 1 and 2.

As an example and in order to demonstrate the 'linear correlation' between $\mathrm{SZ}_{\mathrm{aME}}$ and $\mathrm{R}(\mathrm{Z})$ in Fig. 12 we plot $\mathrm{SZ}_{\mathrm{aME}} /\left(\mathrm{SZ}_{\mathrm{aME}}\right)_{\max }$ versus $\mathrm{R}(\mathrm{Z}) / \mathrm{R}(\mathrm{Z})_{\max }$. The slope of its linear regression line represents the scaling factor $\mathrm{k}_{\mathrm{SZ}}$ in our equation (1) for the case $\mathrm{SZ}_{\mathrm{aME}}$ and $\mathrm{R}(\mathrm{Z})$.

Equations (1) and (2) correlate quantitatively both the size of an atom and its ability to attract different atoms with two different ways of counting the chemical elements in the Periodic Table.

In Table $2 \mathrm{c}$ we introduce an additional enumeration of the elements in Meier's Periodic Table, called 'diagonal number' $\mathrm{DN}_{\mathrm{ME}}$, whereby the enumeration of the elements follows diagonal lines. Its starts with $\mathrm{He}$ and ends with Fr following the general trend from top $\rightarrow$ down in first priority and left $\rightarrow$ right in second priority.

In Fig. $13 \mathrm{DN}_{\mathrm{ME}} /\left(\mathrm{DN}_{\mathrm{ME}}\right)_{\max }$ and our calculated $\mathrm{SZ}_{\mathrm{aME}} /\left(\mathrm{SZ}_{\mathrm{aME}}\right)_{\max }$ versus $\mathrm{PN}_{\mathrm{ME}}$ are shown. The only significant differences are observed for the first three group numbers GN 1-3, but the two functions are remarkably similar. This observation shows that the atomic size can be directly obtained with this alternative kind of enumeration within Meier's Periodic Table. It might open a more direct approximation of the atomic size of the elements and possibly other derived elemental-property parameters using AN and PN.

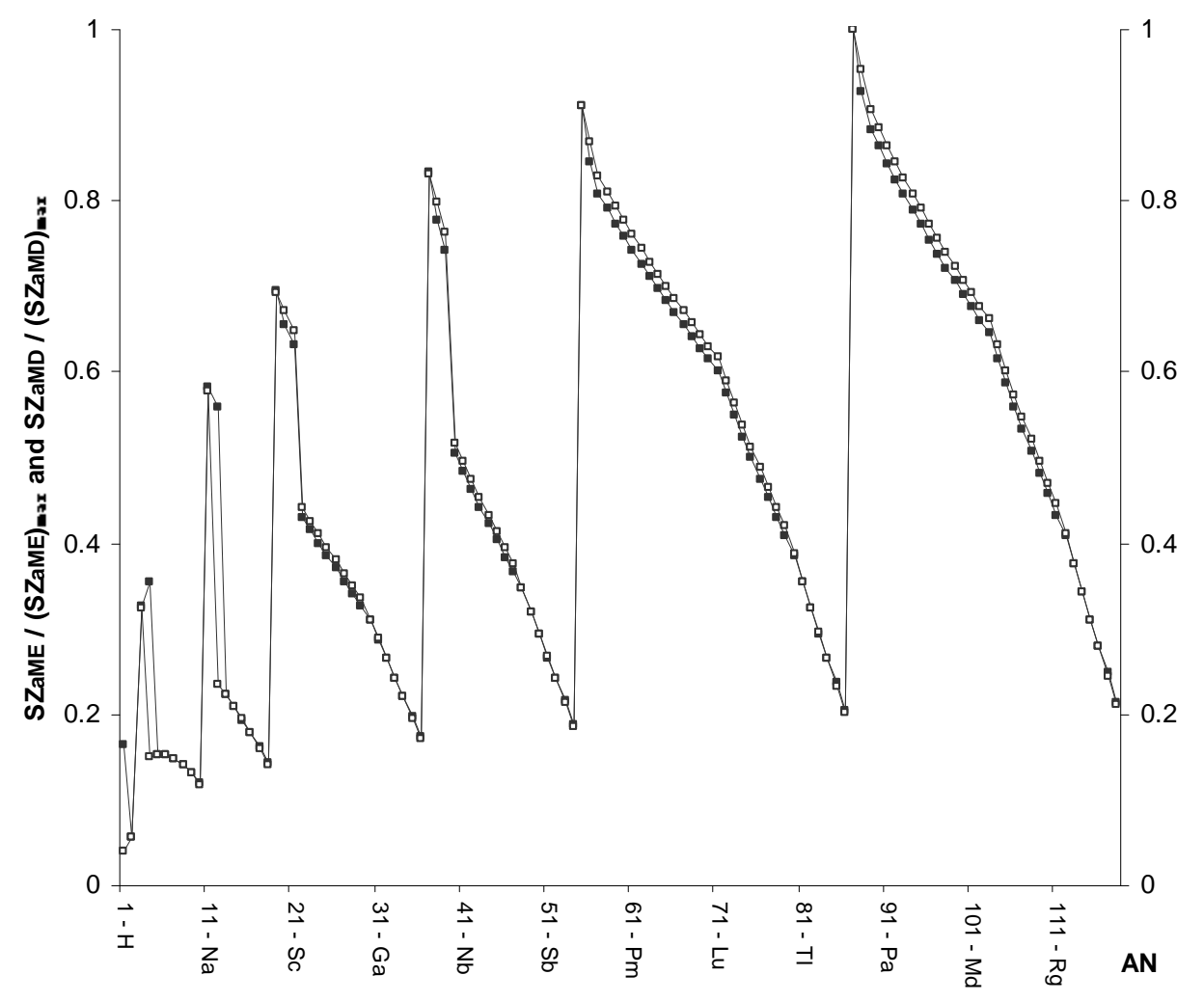

Fig. 8 Atomic size $\mathrm{SZ}_{\mathrm{aME}}$ and $\mathrm{SZ}_{\mathrm{aMD}}$ (normalized to $\left(\mathrm{SZ}_{\mathrm{aME}}\right)_{\max }$ and $\left.\left(\mathrm{SZ}_{\mathrm{aMD}}\right)_{\max }\right)$ versus atomic number $\mathrm{AN}$; $\mathrm{SZ}_{\mathrm{aME}} /\left(\mathrm{SZ}_{\mathrm{aME}}\right)_{\max }, \square \mathrm{SZ}_{\mathrm{aMD}} /\left(\mathrm{SZ}_{\mathrm{aMD}}\right)_{\max }$. For the calculation of $\mathrm{SZ}_{\mathrm{aME}}$ we used the periodic number $\mathrm{PN}_{\mathrm{ME}}$ of Meyer's Periodic System (Table 2a), while for the calculation of $\mathrm{SZ}_{\mathrm{aMD}}$ we used the periodic number $\mathrm{PN}$ of Mendeleyev's Periodic System (Table 2b). 


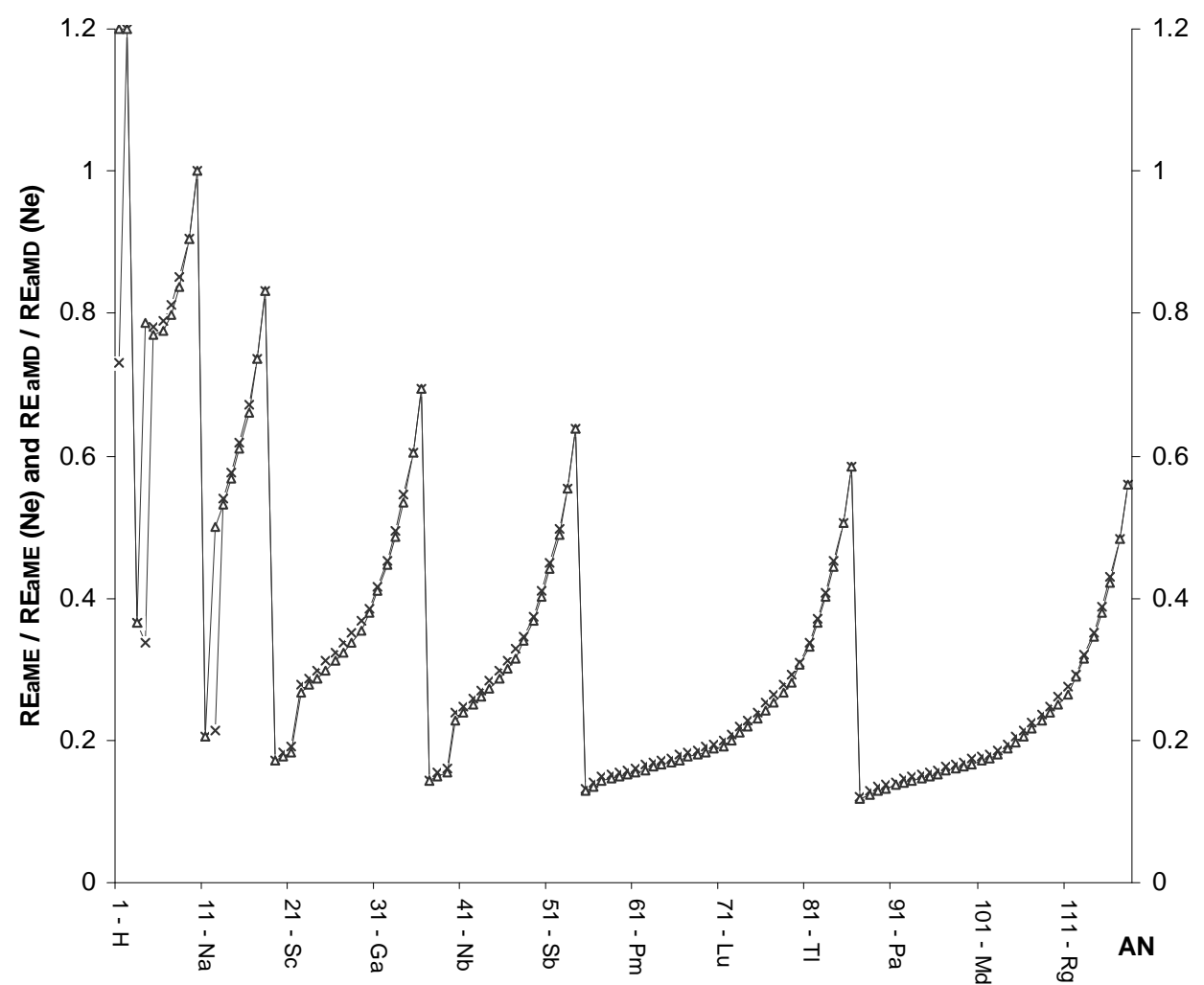

Fig. 9 Atomic reactivity $R E_{a M E}$ and $R E_{a M D}$ (normalized to $R E_{a M E}(\mathrm{Ne})$ and $R E_{a M D}(\mathrm{Ne})$ ) versus atomic number AN; $\times \mathrm{RE}_{\mathrm{aME}} / \mathrm{RE}_{\mathrm{aME}}(\mathrm{Ne}), \triangle \mathrm{RE}_{\mathrm{aMD}} / \mathrm{RE}_{\mathrm{aMD}}(\mathrm{Ne})$. The calculation of $\mathrm{RE}_{\mathrm{aME}}$ is based on Meyer's Periodic System (Table 2a), while the calculation of $\mathrm{RE}_{\mathrm{aMD}}$ is based on Mendeleyev's Periodic System (Table 2b).

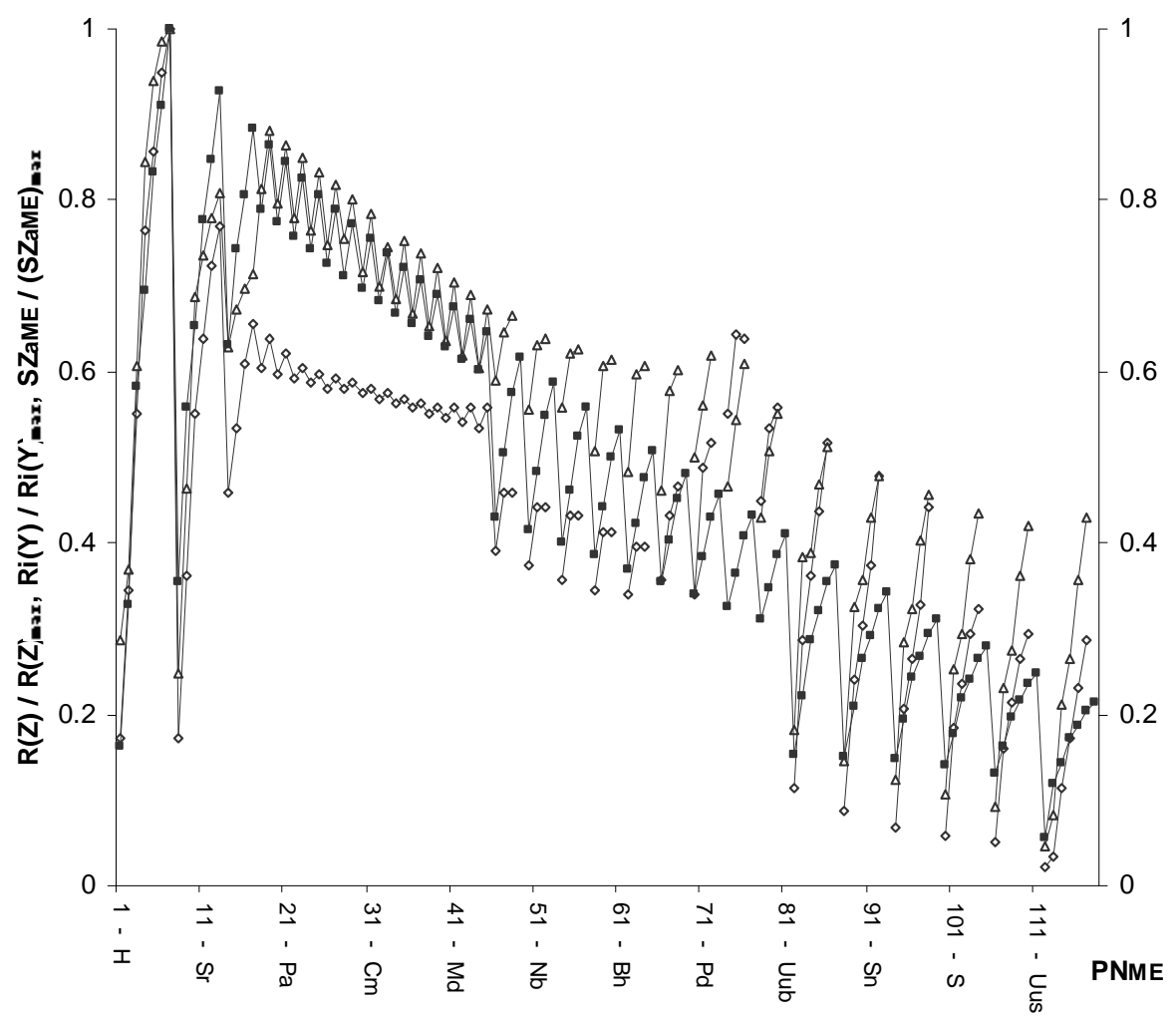

Fig. 10 Pseudo-potential radii according to Zunger $R(Z)$, ionic radii according to Yagoda $R i(Y)$ and calculated atomic size $\mathrm{SZ}_{\mathrm{aME}}$ (normalized to $\mathrm{R}(\mathrm{Z})_{\max }, \mathrm{Ri}(\mathrm{Y})_{\max },\left(\mathrm{SZ}_{\mathrm{aME}}\right)_{\max }$, respectively) versus periodic number $\mathrm{PN}_{\mathrm{ME}} ; \triangle \mathrm{R}(\mathrm{Z}) / \mathrm{R}(\mathrm{Z})_{\max }, \diamond \mathrm{Ri}(\mathrm{Y}) / \mathrm{Ri}(\mathrm{Y})_{\max }$, $\mathrm{SZ}_{\mathrm{aME}} /\left(\mathrm{SZ}_{\mathrm{aME}}\right)_{\max }$. In the case of $\mathrm{R}(\mathrm{Z})$ (the pseudopotential radii according to Zunger, where no published data exist for the f-elements) we estimated the $R(Z)$ values based on a linear dependence for $\mathrm{QN} 6$ between $\mathrm{R}(\mathrm{Z})=3.55$ for $\mathrm{Ce}$ and $\mathrm{R}(\mathrm{Z})=2.64$ for $\mathrm{Lu}$, as well as for $\mathrm{QN} 7$ between $\mathrm{R}(\mathrm{Z})=3.85$ for $\mathrm{Th}$ and $\mathrm{R}(\mathrm{Z})=2.94$ for $\mathrm{Lr}$. 


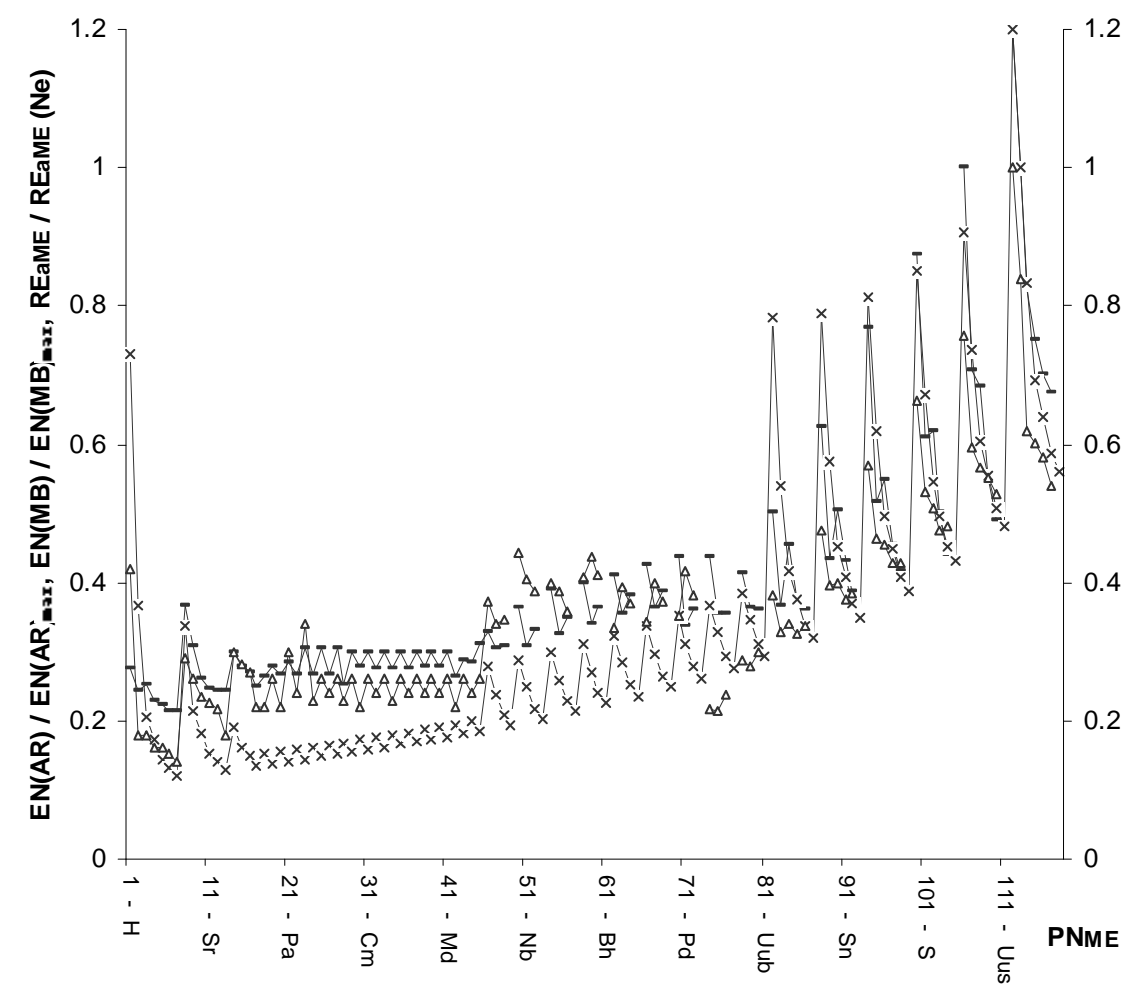

Fig. 11 Electronegativity according to Allred and Rochow EN(AR), electronegativity according to Martynov and Batsanov EN(MB), and calculated atomic reactivity $\mathrm{RE}_{\mathrm{aME}}$ (normalized to $\mathrm{EN}(\mathrm{AR})_{\max }, \mathrm{EN}(\mathrm{MB})_{\max }$ and $\mathrm{RE}_{\mathrm{aME}}(\mathrm{Ne})$, respectively) versus periodic number $\mathrm{PN}_{\mathrm{ME}} ;-\mathrm{EN}(\mathrm{AR}) / \mathrm{EN}(\mathrm{AR})_{\max }, \triangle \mathrm{EN}(\mathrm{MB}) / \mathrm{EN}(\mathrm{MB})_{\max }$, $\times \mathrm{RE}_{\mathrm{aME}} / \mathrm{RE}_{\mathrm{aME}}(\mathrm{Ne})$.

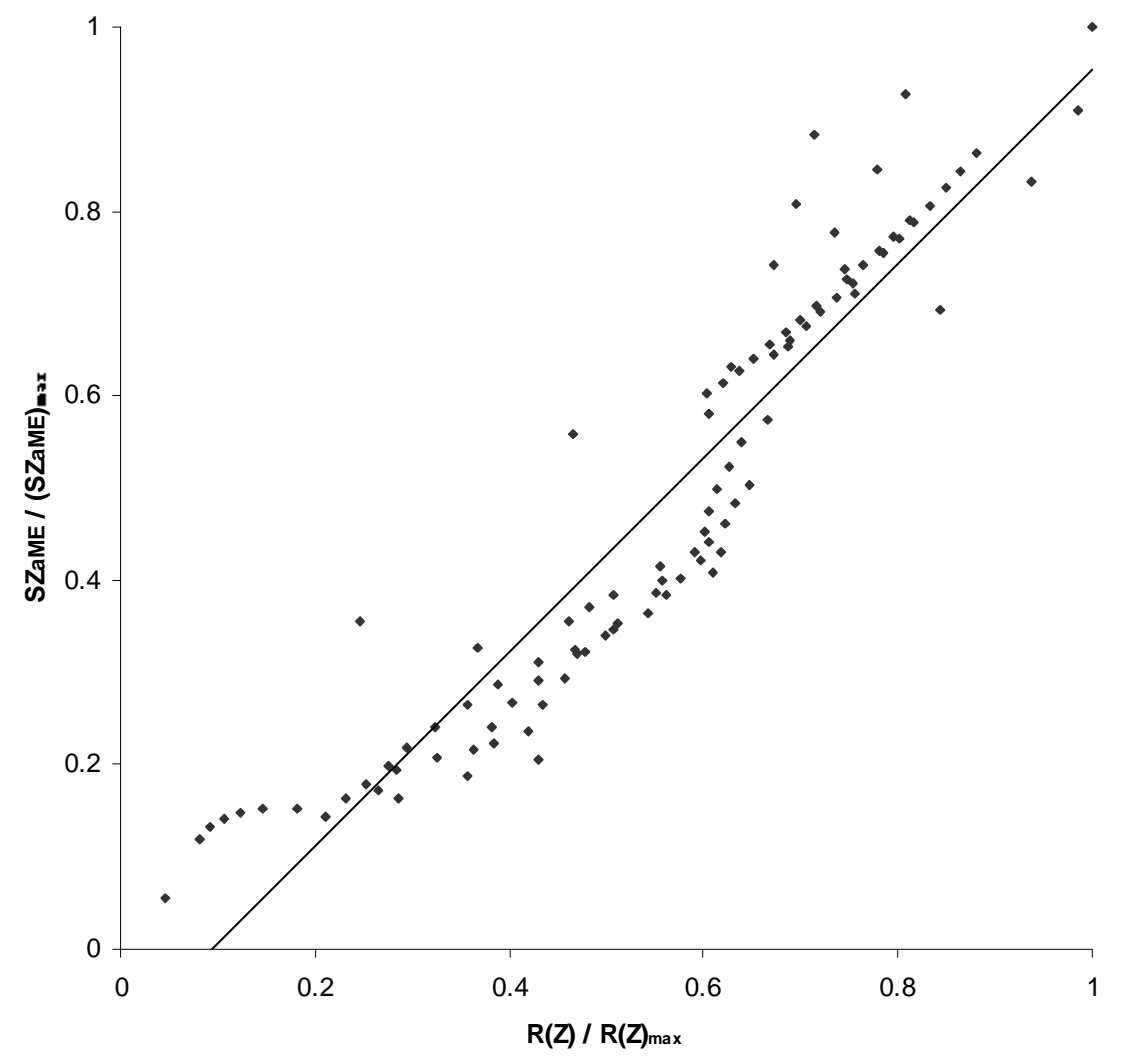

Fig. 12 Atomic size $\mathrm{SZ}_{\mathrm{aME}}$ (normalized to $\left(\mathrm{SZ}_{\mathrm{aME}}\right)_{\max }$ ) versus pseudo-potential radii according to Zunger $\mathrm{R}(\mathrm{Z})$ (normalized to $\mathrm{R}(\mathrm{Z})_{\max }$ ) with linear regression line. In the case of $\mathrm{R}(\mathrm{Z})$, the pseudo-potential radii according to Zunger (where no published data exist for the f-elements) we estimated the $R(Z)$ values based on a linear dependence for QN 6 between $\mathrm{R}(\mathrm{Z})=3.55$ for Ce and $\mathrm{R}(\mathrm{Z})=2.64$ for $\mathrm{Lu}$, as well as for $\mathrm{QN} 7$ between $\mathrm{R}(\mathrm{Z})$ $=3.85$ for $\mathrm{Th}$ and $\mathrm{R}(\mathrm{Z})=2.94$ for $\mathrm{Lr}$. 


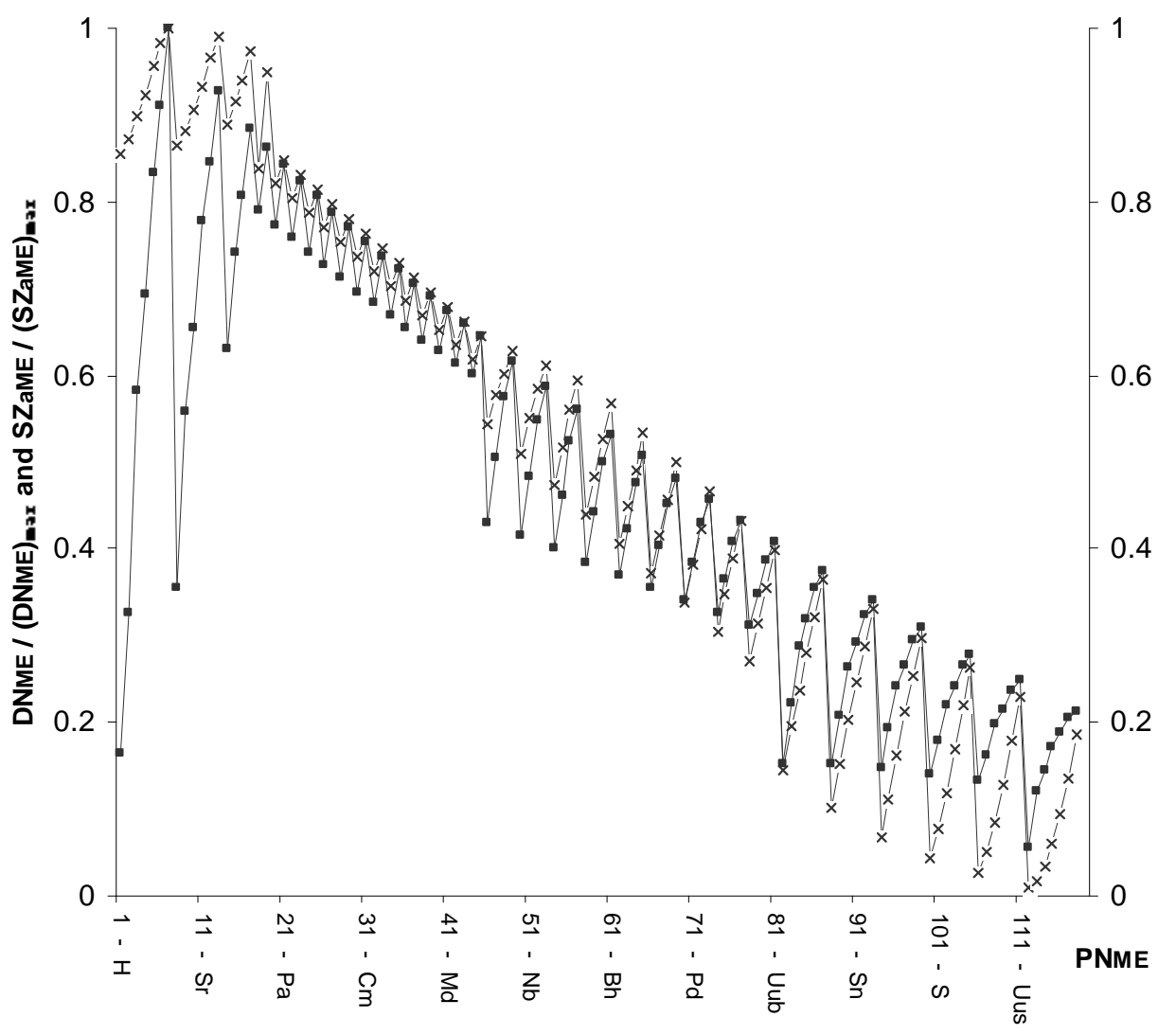

Fig. 13 Atomic size $\mathrm{SZ}_{\mathrm{aME}}$ (normalized to $\left.\left(\mathrm{SZ}_{\mathrm{aME}}\right)_{\max }\right)$ and $\mathrm{DN}_{\mathrm{ME}} /\left(\mathrm{DN}_{\mathrm{ME}}\right)_{\max }$. $\mathrm{DN}_{\mathrm{ME}}$ is defined by a diagonal

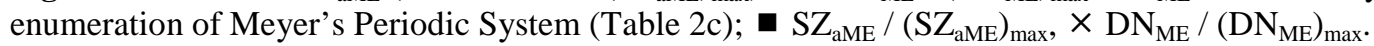

From the different elemental-property parameter patterns we could so far formulate the atomic size and the atomic reactivity as functions of $\mathrm{AN}$ and $\mathrm{PN}$. We do get the impression that all additional patterns like e.g. the atomic affinity pattern and the atomic density pattern can be formulated as function of AN and PN. As an example the density (= atomic mass / atomic volume) may easily be derived from the patterns discussed above, in this case from the atomic number pattern and the atomic size pattern. As can be seen in Fig. 3 the atomic affinity pattern group members show for the GN 1-3 and GN 13-18 elements the general trend from the atomic reactivity pattern, while for the GN 4-12 the trend follows the atomic size pattern group.

In our analysis of the atomic environment types AET $[19,20]$ we observed that in a crystal structure the atomic size, the atomic reactivity and the atomic affinity determine the AET. The analysis of over 200,000 atomic positions in binary, ternary and quaternary compounds revealed that less than 60 geometrically different AET's (the majority belonging to only 24 AET's) are observed in experimental data. The AET's are governed by the size of the constituent chemical elements $\mathrm{A}, \mathrm{B}, \mathrm{C}, \ldots$, the interactions $\mathrm{A}-\mathrm{B}$, A-C, B-C, ..., as well as A-A, B-B, C-C, ... (which are represented by the corresponding shortest interatomic distances).

\section{Elemental-property parameters used for parameterization of materials properties}

Previous papers, such as that on the prediction of compound formers/non-formers in binary, ternary and quaternary systems [17], as well as that on the atomic environment (AET) prediction for equiatomic binary compounds [18], do well support the postulate: "Structure-sensitive properties of materials are quantitatively described by the elemental-property parameters of the constituent chemical elements." Now as we obtained a direct link between the fundamental elemental parameters $\mathrm{AN}$ and $\mathrm{PN}$ and the derived elemental-property parameters $\mathrm{SZ}_{\mathrm{a}}$ and $\mathrm{RE}_{\mathrm{a}}$, we can generalize our postulate to the following statement: "Structure-sensitive material properties are quantitatively determined by the elemental-property parameters AN and PN (or simple mathematical functions of them) of the constituent chemical elements." This generalization is an important link to strategically explore structure-sensitive properties of materials.

In [17] we gained from different compilations [2127] the following numbers of distinct information about compound-forming, respectively non-forming systems: 2016 binary systems, 6382 ternary systems and 7021 quaternary systems. For that work, 44 binary non-forming systems were discarded because either 
we found contradictory information or the information was based on one schematic phase diagram (either from old experimental work or from calculated phase diagrams (CALPHAD work): $\mathrm{Ag}-\mathrm{U}, \mathrm{Al}-\mathrm{Cs}, \mathrm{Al}-\mathrm{K}$, $\mathrm{Al}-\mathrm{Na}, \mathrm{Au}-\mathrm{B}, \mathrm{Au}-\mathrm{Ge}, \mathrm{Au}-\mathrm{P}, \mathrm{B}-\mathrm{Bi}, \mathrm{B}-\mathrm{Cd}, \mathrm{B}-\mathrm{Cu}$, $\mathrm{B}-\mathrm{Ga}, \mathrm{B}-\mathrm{Ge}, \mathrm{B}-\mathrm{Hg}, \mathrm{B}-\mathrm{Pb}, \mathrm{B}-\mathrm{Sb}, \mathrm{B}-\mathrm{Sn}, \mathrm{B}-\mathrm{Tl}$, $\mathrm{B}-\mathrm{Zn}, \mathrm{Ba}-\mathrm{Ni}, \mathrm{Be}-\mathrm{Li}, \mathrm{Be}-\mathrm{Na}, \mathrm{Bi}-\mathrm{Si}, \mathrm{C}-\mathrm{Co}, \mathrm{C}-\mathrm{Ge}$, C-Ir, C-Ni, Cs-Li, Cs-Mg, Cu-Li, K-Li, K-Mg, $\mathrm{Li}-\mathrm{Mg}, \mathrm{Li}-\mathrm{Ni}, \mathrm{Li}-\mathrm{Pu}, \mathrm{Li}-\mathrm{Rb}, \mathrm{Mg}-\mathrm{Na}, \mathrm{Mg}-\mathrm{Rb}$, $\mathrm{Mg}-\mathrm{U}, \mathrm{Re}-\mathrm{Sb}, \mathrm{S}-\mathrm{Te}, \mathrm{Sb}-\mathrm{W}, \mathrm{Si}-\mathrm{Sn}, \mathrm{Si}-\mathrm{Tl}, \mathrm{Si}-\mathrm{Zn}$. The remaining three data sets: 2318 binary systems (with the halides added), 6266 ternary systems and 6913 quaternary systems are used throughout the present work.

Below we give the two conditions (criteria), which we used to decide whether a binary, ternary or quaternary system belongs to a former or non-former system. These two definitions (here explicitly explained for the ternary case) for separating formers from non-formers are based on the following fundamentals:

- Description of crystal structure within the

framework of space group theory,

- Gibbs' phase rule.

As the majority of the data are gained under normal conditions ( $\mathrm{T}=298 \mathrm{~K}$, and atmospheric pressure) and phase equilibrium, we take this as our standard reference.

Definition 1: A compound-forming system possesses at least one ternary compound separated by three two-phase regions involving three adjacent chemical element(s) and/or binary compound(s) and/or ternary compound(s) in at least one complete isothermal section. In those cases where no phase diagram for an A-B-C system is known, but a ternary compound with a ternary crystal structure is reported, then this system is of course accepted as a compound former.

Definition 2: A ternary system is a non-former when no three-phase region or complete solid solution respectively, is shown in at least one complete isothermal section. In those cases where no complete isothermal section for an $\mathrm{A}-\mathrm{B}-\mathrm{C}$ system is known, a ternary system will be a non-former when all its three binary boundary systems are non-formers. Based on this criterion we derived 2118 ternary and 4274 quaternary non-formers from 634 published binary non-former phase diagrams. This criterion has been confirmed, so far, by all published ternary isothermal sections.

Based on the criterion that a ternary system is a former when at least one ternary 'line' phase with a ternary crystal structure is published, we found 4264 ternary formers. Note that this simple criterion excludes pseudo-ternary phases, which are solid solutions of binary compounds.

In order to test the parameterization power of $\mathrm{SZ}_{\mathrm{a}}$ and $\mathrm{RE}_{\mathrm{a}}$ we applied the program "DISCOVERY" [28] on the above-mentioned data sets. The aim of this process is to search systematically for salient $2 \mathrm{D}$ - and
3D-features sets, to visualize them and to correlate quantitatively the materials properties of these chemical elements (in this case: formers/non-formers) with the elemental-property parameters of their constituent chemical elements. This is done in a threestep procedure:

1) Collection of published (experimental and theoretical) elemental-property parameters and calculation of $\mathrm{SZ}_{\mathrm{a}}$ and $\mathrm{RE}_{\mathrm{a}}$ (Tables 1 and 2).

2) Application of an automatic generator for $2 \mathrm{D}$ - and 3D-features sets resulting from combinations of elemental-property parameters and mathematical operators. We introduced the operators $+,-, *, /$, max. and min. to link the elemental-property parameters (EP) of the different constituents, say A, B, C for ternary systems, to form global elemental-property parameters EP1(tot) = EP1(A) op EP1(B) op EP1(C).

3) Automatic high-quality separation detection and its visualization.

The general idea is very simple: Assume that we consider 2000 data points (1000 ternary formers and 1000 ternary non-formers) in a plot of a selected 3Dfeatures set. We check now for each point whether their $\mathrm{n}$ nearest neighbors in the plot are of the same class or not, here formers or non-formers, and make a statistical analysis for all 2000 data points $(n=1, \ldots$, 50 , depending on the standard wanted).

As a first example, we ran the program "DISCOVERY" on all elemental-property parameters belonging to each pattern group listed in Tables 1a, 1b. Using all mathematical operators mentioned above, we give the best separation results listed in Table 3a. The success of the separation is indicated by the hit rate, e.g. $90 \%(n=1) \rightarrow 44 \%(n=50)$. This means that $90 \%$ of all data points have a nearest neighbor of the same kind and $44 \%$ of all data points have 50 nearest neighbors of the same kind taking the reference data point as the center of a circular area. Table $3 b$ shows the results of the best $2 \mathrm{D}$-features sets using AN, PN, and the calculated elemental-property parameters $\mathrm{SZ}_{\mathrm{a}}$ and $\mathrm{RE}_{\mathrm{a}}$. The 6266 ternary systems mentioned above were used as test material.

A detailed comparison for the separation efficiency of the various elemental-property parameters of the atomic size and atomic reactivity patterns groups is given in Tables 4 and 5, respectively. It is evident that $\mathrm{SZ}_{\mathrm{aME}}\left(\mathrm{AN}, \mathrm{PN}_{\mathrm{ME}}\right)$ as well as $\mathrm{RE}_{\mathrm{aME}}\left(\mathrm{AN}, \mathrm{PN}_{\mathrm{ME}}\right)$ (in all cases the normalized values are used) improve the separation between compound-forming and nonforming systems. Similar improvements have been achieved for binary and quaternary data sets.

Figs. 14-16 show the best "overall results" 2Dfeatures sets for binary, ternary and quaternary chemical systems. We are aware that by using a 2Dfeatures set, instead of a 3D-features set, we are loosing some information. Nevertheless by using the appropriate $2 \mathrm{D}$-projection of the $3 \mathrm{D}$-features set we loose only about $3 \%$ accuracy, but get the advantage that the given figures are easy to interpret. Based on our statistical analysis several 2D- and 3D-features 
Table 3 (a) Result of the best 3D-features sets using the published elemental-property data sets (Tables 1a, 1b). The hit rate per ternary system decreases from e.g. $97 \%$ with $n=1$ correct neighbor to $71 \%$ with $n=50$ correct nearest neighbors for the case of the reactivity pattern group. (b) Result of the best 2D-features sets using the calculated elemental-property data sets (Tables $2 \mathrm{a}, 2 \mathrm{~b}$ ). The hit rate per ternary system decreases from e.g. $99 \%$ with $n=1$ correct neighbor to $86 \%$ with $n=50$ correct nearest neighbors for the case of $\mathrm{RE}_{\mathrm{aME}}$.

(a)

\begin{tabular}{|c|c|c|}
\hline $\begin{array}{l}\text { Using all data sets listed in Tables } 1 \mathrm{a}, 1 \mathrm{~b} \\
\text { for each group }\end{array}$ & $\begin{array}{l}\text { Elemental-property } \\
\text { parameter as listed in Tables } \\
1 \mathrm{a}, 1 \mathrm{~b}\end{array}$ & $\begin{array}{l}\text { Separation result in the best 3D- } \\
\text { features set }\end{array}$ \\
\hline I) Atomic number pattern group & $\begin{array}{l}\text { AN, QN, AM, nc }(C), \operatorname{nc}(S), \\
\text { cma(Mo), cma }(\mathrm{Cu}), \text { aes }\end{array}$ & $90 \%(\mathrm{n}=1) \rightarrow 44 \%(\mathrm{n}=50)$ \\
\hline II) Periodic number pattern group & $\begin{array}{l}\mathrm{PN}_{\mathrm{ME}}, \mathrm{PN}_{\mathrm{MD}}, \mathrm{PN}(\mathrm{P}), \mathrm{VE}, \\
\mathrm{GN}\end{array}$ & $99 \%(\mathrm{n}=1) \rightarrow 88 \%(\mathrm{n}=50)$ \\
\hline i) Atomic size pattern group & $\begin{array}{l}\text { R(Z), Ri(Y), Rc(P), } \\
\text { Rm(WG), Rve(S), Rce(S), } \\
\text { R(M), R(VD) }\end{array}$ & $98 \%(\mathrm{n}=1) \rightarrow 75 \%(\mathrm{n}=50)$ \\
\hline ii) Atomic reactivity pattern group & $\begin{array}{l}\mathrm{EN}(\mathrm{MB}), \mathrm{EN}(\mathrm{P}), \mathrm{EN}(\mathrm{AR}), \\
\mathrm{EN}(\mathrm{abs}), \mathrm{IE}(\text { first }), \mathrm{CP}(\mathrm{M}), \\
\text { wf, n(WS) }\end{array}$ & $97 \%(\mathrm{n}=1) \rightarrow 71 \%(\mathrm{n}=50)$ \\
\hline
\end{tabular}

(b)

\begin{tabular}{l|l|l}
\hline Belonging to patterns listed in Tables 1a, 1b & $\begin{array}{l}\text { Derived elemental- } \\
\text { property parameters as } \\
\text { listed in Tables 2a, 2b }\end{array}$ & $\begin{array}{l}\text { Separation result in the best 2D- } \\
\text { features set }\end{array}$ \\
\hline I) Atomic number pattern group & $\mathrm{AN}$ & $88 \%(\mathrm{n}=1) \rightarrow 40 \%(\mathrm{n}=50)$ \\
II) Periodic number pattern group & $\mathrm{PN}_{\mathrm{ME}}$, & $99 \%(\mathrm{n}=1) \rightarrow 84 \%(\mathrm{n}=50)$ \\
& $\mathrm{PN}_{\mathrm{MD}}$ & $\mathrm{SZ}$ \\
i) Atomic size pattern group & $\mathrm{SZ}_{\mathrm{aME}}$, & $99 \%(\mathrm{n}=1) \rightarrow 84 \%(\mathrm{n}=50)$ \\
& $\mathrm{RE}_{\mathrm{aME}}$, & $99 \%(\mathrm{n}=1) \rightarrow 86 \%(\mathrm{n}=50)$ \\
& $\mathrm{RE}_{\mathrm{aMD}}$ & \\
\hline
\end{tabular}

Table 4 Results of the best 2-D features sets using only elemental parameters belonging to the atomic size pattern. The hit rate per ternary system decreases from e.g. $98.9 \%$ with $\mathrm{n}=1$ correct neighbor to $83.2 \%$ with 50 correct nearest neighbors for the case of $\mathrm{SZ}_{\mathrm{aME}}$.

\begin{tabular}{l}
\hline i) Atomic size pattern group \\
\hline $\mathrm{R}(\mathrm{VD}):$ Radii according to Villars and Daams \\
(derived from their V compilation) \\
$\mathrm{R}(\mathrm{M})$ : Radii according to Miedema \\
(derived from his $\mathrm{V}^{2 / 3}$ compilation) \\
Rve(S): Valence electron distance according to Schubert \\
$\mathrm{Rce}(\mathrm{S})$ : Core electron distance according to Schubert \\
$\mathrm{Rm}(\mathrm{WG})$ : Metal radii according to Waber and Gschneidner \\
$\mathrm{Rc}(\mathrm{P}):$ Covalent radii according to Pauling \\
$\mathrm{Ri}(\mathrm{Y})$ : Ionic radii according to Yagoda \\
$\mathrm{R}(\mathrm{Z})$ : Pseudo-potential radii according to Zunger \\
$\mathrm{SZ}$ aME $\left(\right.$ AN, PN $\left.\mathrm{ME}_{\mathrm{ME}}\right)$ : Atomic size, present calculation \\
\hline
\end{tabular}

Best separation result
$81.3 \%(\mathrm{n}=1) \rightarrow 5.5 \%(\mathrm{n}=50)$
$81.3 \%(\mathrm{n}=1) \rightarrow 5.7 \%(\mathrm{n}=50)$
$84.3 \%(\mathrm{n}=1) \rightarrow 15.6 \%(\mathrm{n}=50)$
$85.6 \%(\mathrm{n}=1) \rightarrow 22.5 \%(\mathrm{n}=50)$
$81.9 \%(\mathrm{n}=1) \rightarrow 33.2 \%(\mathrm{n}=50)$
$87.3 \%(\mathrm{n}=1) \rightarrow 38.3 \%(\mathrm{n}=50)$
$88.7 \%(\mathrm{n}=1) \rightarrow 48.1 \%(\mathrm{n}=50)$
$97.9 \%(\mathrm{n}=1) \rightarrow 75.2 \%(\mathrm{n}=50)$
$98.9 \%(\mathrm{n}=1) \rightarrow 83.2 \%(\mathrm{n}=50)$

sets have better separation results (in the range of 3-5\%). The plots shown here reflect clearly the validity of Pauling's electronegativity- and Laves' geometrical-concepts shown by its atomic reactivity differences (y-axis) and its atomic size ratios (x-axis), respectively.

These plots demonstrate that for compound formation the atomic reactivity difference is more important than the atomic size ratio. Furthermore in plots using $\mathrm{SZ}_{\mathrm{a}}$ and $\mathrm{RE}_{\mathrm{a}}$ Meyer's Periodic System is more efficient than Mendeleyev's System. However, in plots where we use PN, it is Mendeleyev's System that is more efficient (Figs. 17, 18).

By using "Pauling's and Laves' axes" we reach for the binary, ternary and quaternary systems the following hit rates: $78.5 \%(\mathrm{n}=1) \rightarrow 39.2 \%(\mathrm{n}=50)$, $97.8 \%(\mathrm{n}=1) \rightarrow 81.0 \%(\mathrm{n}=50), 99.9 \%(\mathrm{n}=1) \rightarrow$ $97.9 \%(n=50)$, respectively. 
Table 5 Results of the best 2-D features sets using only elemental parameters belonging to the atomic reactivity pattern. The hit rate per ternary system decreases from e.g. $98.7 \%$ with 1 correct neighbor to $84.9 \%$ with 50 correct nearest neighbors for the case of $\mathrm{RE}_{\mathrm{aME}}$.

\begin{tabular}{l|l}
\hline ii) Atomic reactivity pattern group & Best separation result \\
\hline $\mathrm{n}(\mathrm{WS}): \mathrm{n}($ Wigner and Seitz) according to Miedema & $90.8 \%(\mathrm{n}=1) \rightarrow 34.3 \%(\mathrm{n}=50)$ \\
EN(MB): Electronegativity according to Martynov \& Batsanov & $93.7 \%(\mathrm{n}=1) \rightarrow 40.9 \%(\mathrm{n}=50)$ \\
wf: Work function & $83.0 \%(\mathrm{n}=1) \rightarrow 49.4 \%(\mathrm{n}=50)$ \\
EN(abs): Absolute electronegativity & $94.4 \%(\mathrm{n}=1) \rightarrow 52.9 \%(\mathrm{n}=50)$ \\
$\mathrm{EN}(\mathrm{P}):$ Electronegativity according to Pauling & $76.6 \%(\mathrm{n}=1) \rightarrow 55.9 \%(\mathrm{n}=50)$ \\
$\mathrm{IE}(\mathrm{first}):$ First ionization energy & $94.7 \%(\mathrm{n}=1) \rightarrow 54.7 \%(\mathrm{n}=50)$ \\
$\mathrm{CP}(\mathrm{M}):$ Chemical potential according to Miedema & $96.1 \%(\mathrm{n}=1) \rightarrow 59.3 \%(\mathrm{n}=50)$ \\
$\mathrm{EN}(\mathrm{AR}):$ Electronegativity according to Allred \& Rochow & $96.6 \%(\mathrm{n}=1) \rightarrow 70.6 \%(\mathrm{n}=50)$ \\
$\mathrm{RE}_{\mathrm{aME}}\left(\mathrm{AN}, \mathrm{PN}_{\mathrm{ME}}\right):$ Atomic reactivity, present calculation & $98.7 \%(\mathrm{n}=1) \rightarrow 84.9 \%(\mathrm{n}=50)$ \\
\hline
\end{tabular}

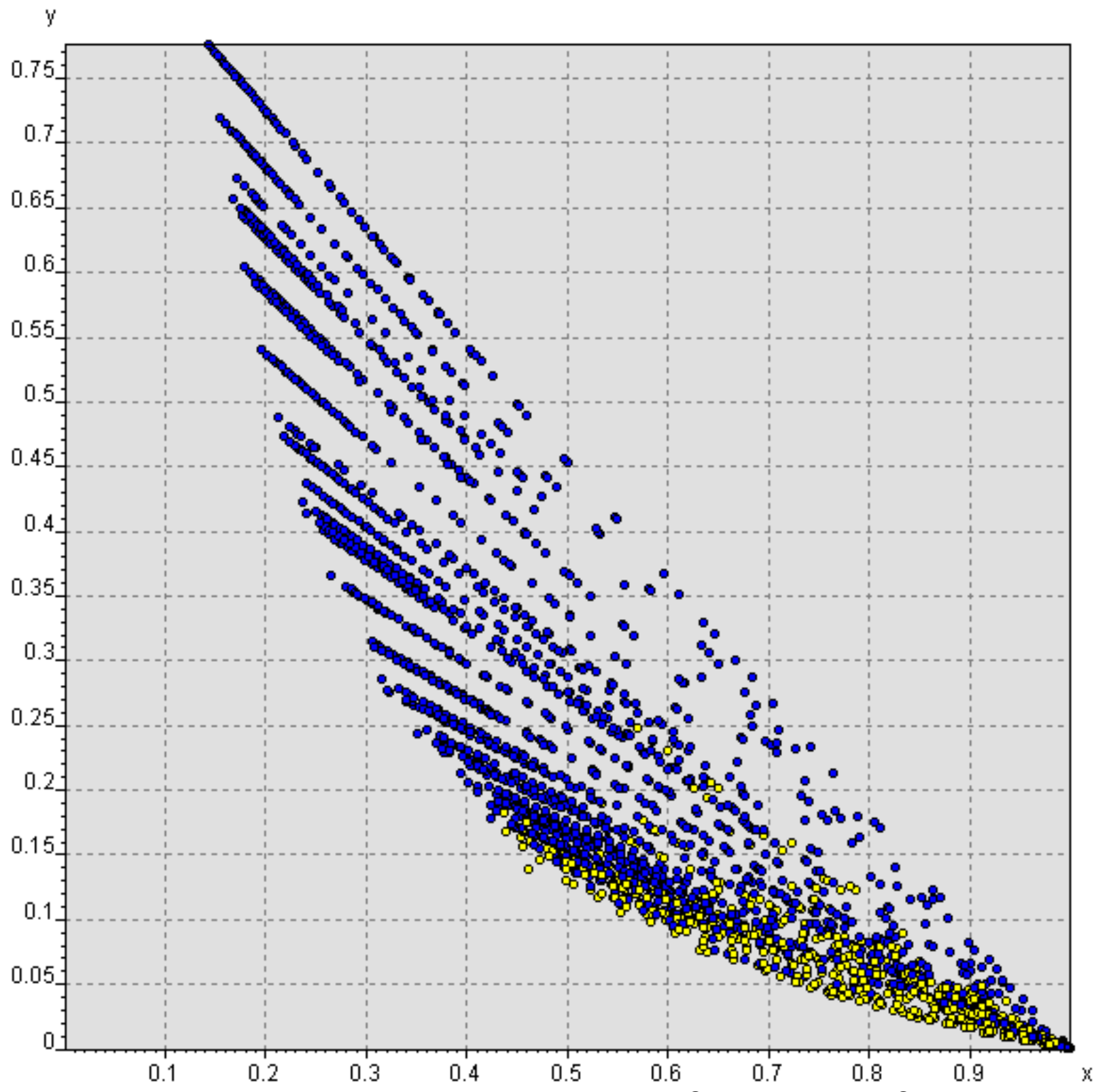

Fig. 14 Separation of 2318 binary systems into compound formers $(O)$ and non-formers $(\bigcirc)$ based on a plot of the absolute difference (y-axis) $\left|\mathrm{RE}_{\mathrm{aME}}(\mathrm{A})-\mathrm{RE}_{\mathrm{aME}}(\mathrm{B})\right| /\left(2 \mathrm{RE}_{\mathrm{aME}}(\mathrm{Ne})\right.$ ) versus the ratio (x-axis) $\mathrm{SZ}_{\mathrm{aME}}$ (A) / $\left(2 \mathrm{SZ}_{\mathrm{aME}}(\mathrm{B})\right)$. For the binary systems the absolute difference $=(|\mathrm{EP}(\mathrm{A})-\mathrm{EP}(\mathrm{B})|) /(\mathrm{n}(\mathrm{n}-1) / 2)$ and for the ratio $[\mathrm{EP}(\mathrm{A}) / \mathrm{EP}(\mathrm{B})] /(\mathrm{n}(\mathrm{n}-1) / 2), \mathrm{EP}(\mathrm{A})<\mathrm{EP}(\mathrm{B})$ and $\mathrm{EP}(\mathrm{A}), \mathrm{EP}(\mathrm{B}) \leq 1$. $\mathrm{EP}(\mathrm{A}), \mathrm{EP}(\mathrm{B})=$ elementalproperty parameters of element $\mathrm{A}$ and $\mathrm{B}$, respectively, and $\mathrm{n}=$ number of elements $=2$. 


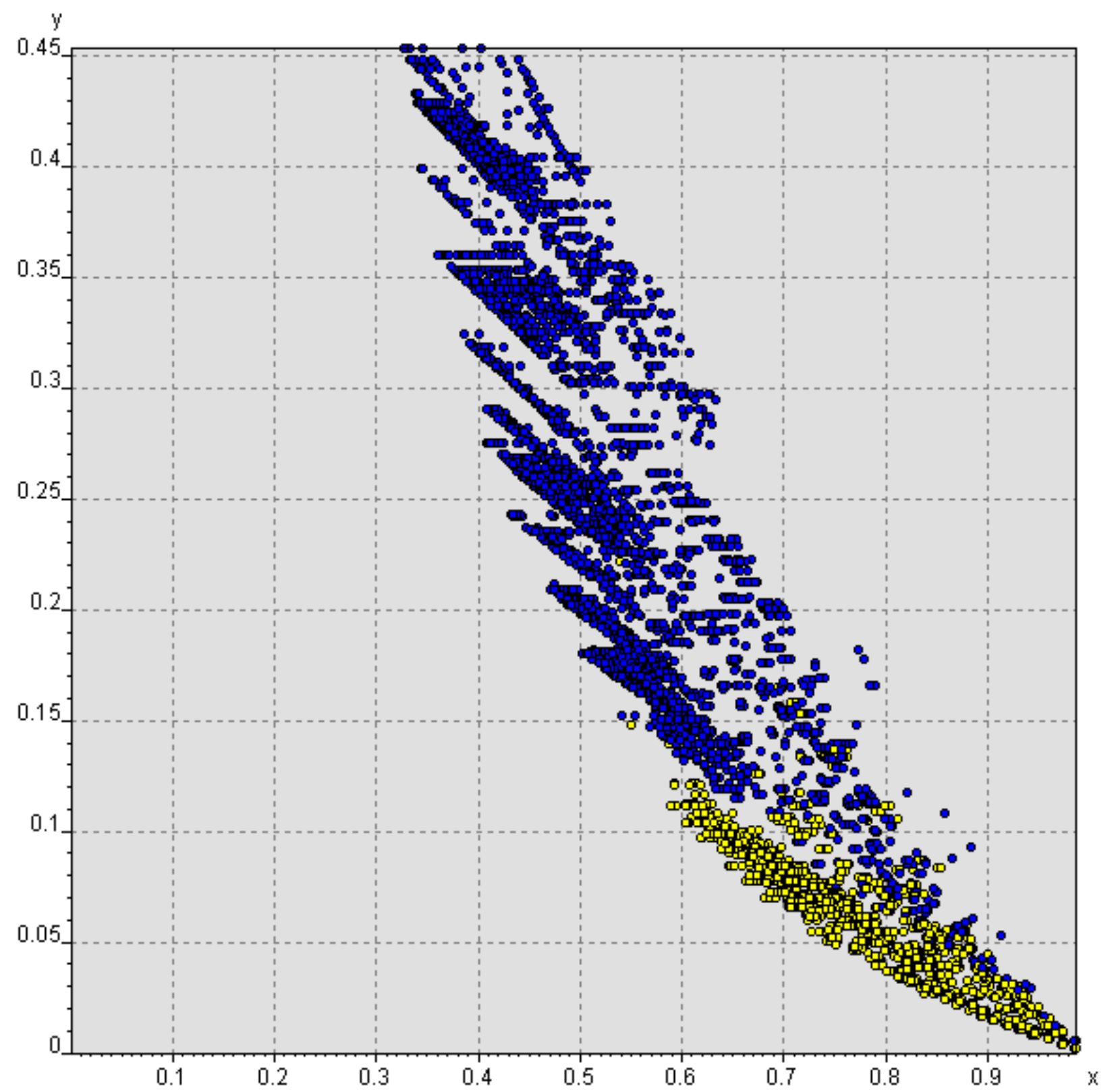

Fig. 15 Separation of 6266 ternary systems into compound formers $(O)$ and non-formers $(\bigcirc)$ based on a plot of the absolute difference (y-axis) $2 / 3\left[\left(\mathrm{RE}_{\mathrm{aME}}(\mathrm{A})-\mathrm{RE}_{\mathrm{aME}}(\mathrm{C})\right) / \mathrm{RE}_{\mathrm{aME}}(\mathrm{Ne})\right]$ versus the ratio (x-axis) $\left[\mathrm{SZ}_{\mathrm{aME}}\right.$ (A) $\left./ \mathrm{SZ}_{\mathrm{aME}}(\mathrm{B})+\mathrm{SZ}_{\mathrm{aME}}(\mathrm{A}) / \mathrm{SZ}_{\mathrm{aME}}(\mathrm{C})+\mathrm{SZ} \mathrm{aME}(\mathrm{B}) / \mathrm{SZ}_{\mathrm{aME}}(\mathrm{C})\right] / 3$. For the ternary systems the absolute difference $=(|\mathrm{EP}(\mathrm{A})-\mathrm{EP}(\mathrm{B})|+|\mathrm{EP}(\mathrm{A})-\mathrm{EP}(\mathrm{C})|+|\mathrm{EP}(\mathrm{B})-\mathrm{EP}(\mathrm{C})|) /(\mathrm{n}(\mathrm{n}-1) / 2)$ and for the ratio $[\mathrm{EP}(\mathrm{A})$ $/ \mathrm{EP}(\mathrm{B})+\mathrm{EP}(\mathrm{A}) / \mathrm{EP}(\mathrm{C})+\mathrm{EP}(\mathrm{B}) / \mathrm{EP}(\mathrm{C})] /(\mathrm{n}(\mathrm{n}-1) / 2)$, with $\mathrm{EP}(\mathrm{A})<\mathrm{EP}(\mathrm{B})<\mathrm{EP}(\mathrm{C})$ and EP $(\mathrm{A}), \mathrm{EP}$ (B), EP (C) $\leq 1$. EP (A), EP (B), EP (C) = elemental-property parameters of element A, B and C, respectively and $n=$ number of elements $=3$.

We like to stress the fact that although the atomic reactivity is the reciprocal of the atomic size, it is justified to use in some cases both in the same plot. In a ternary system A-B-C in general the element with the maximal atomic size has the minimal atomic reactivity. This means e.g. in a max. $\left(\mathrm{SZ}_{\mathrm{a}}(\mathrm{A}, \mathrm{B}, \mathrm{C})\right)$ versus max. $\left(R_{a}(A, B, C)\right)$ plot that only the $B$-element is not taken into consideration, otherwise the $\mathrm{B}$ - and C-elements would be ignored.
For binary systems, comparing the results of Fig. 14 with those of Fig. 17, a much more satisfactory separation is achieved using a max. $\left[\mathrm{PN}_{\mathrm{ME}}\right.$ (A) / $\left.\left(\mathrm{PN}_{\mathrm{ME}}\right)_{\max }, \mathrm{PN}_{\mathrm{ME}}(\mathrm{B}) /\left(\mathrm{PN}_{\mathrm{ME}}\right)_{\max }\right]$ versus $\left[\mathrm{PN}_{\mathrm{ME}}(\mathrm{A}) /\right.$ $\left.\left(\mathrm{PN}_{\mathrm{ME}}\right)_{\max } \times \mathrm{PN}_{\mathrm{ME}}(\mathrm{B}) /\left(\mathrm{PN}_{\mathrm{ME}}\right)_{\max }\right]$ plot, with a separation of $95.6 \%(n=1) \rightarrow 44.5 \%(n=50)$. This plot is further improved (see Fig. 18) when the Meyer numbers $\mathrm{PN}_{\mathrm{ME}}$ are replaced by the Mendeleyev numbers $\mathrm{PN}_{\mathrm{MD}}$ to $95.6 \%(\mathrm{n}=1) \rightarrow 55.3 \%(\mathrm{n}=50)$. 


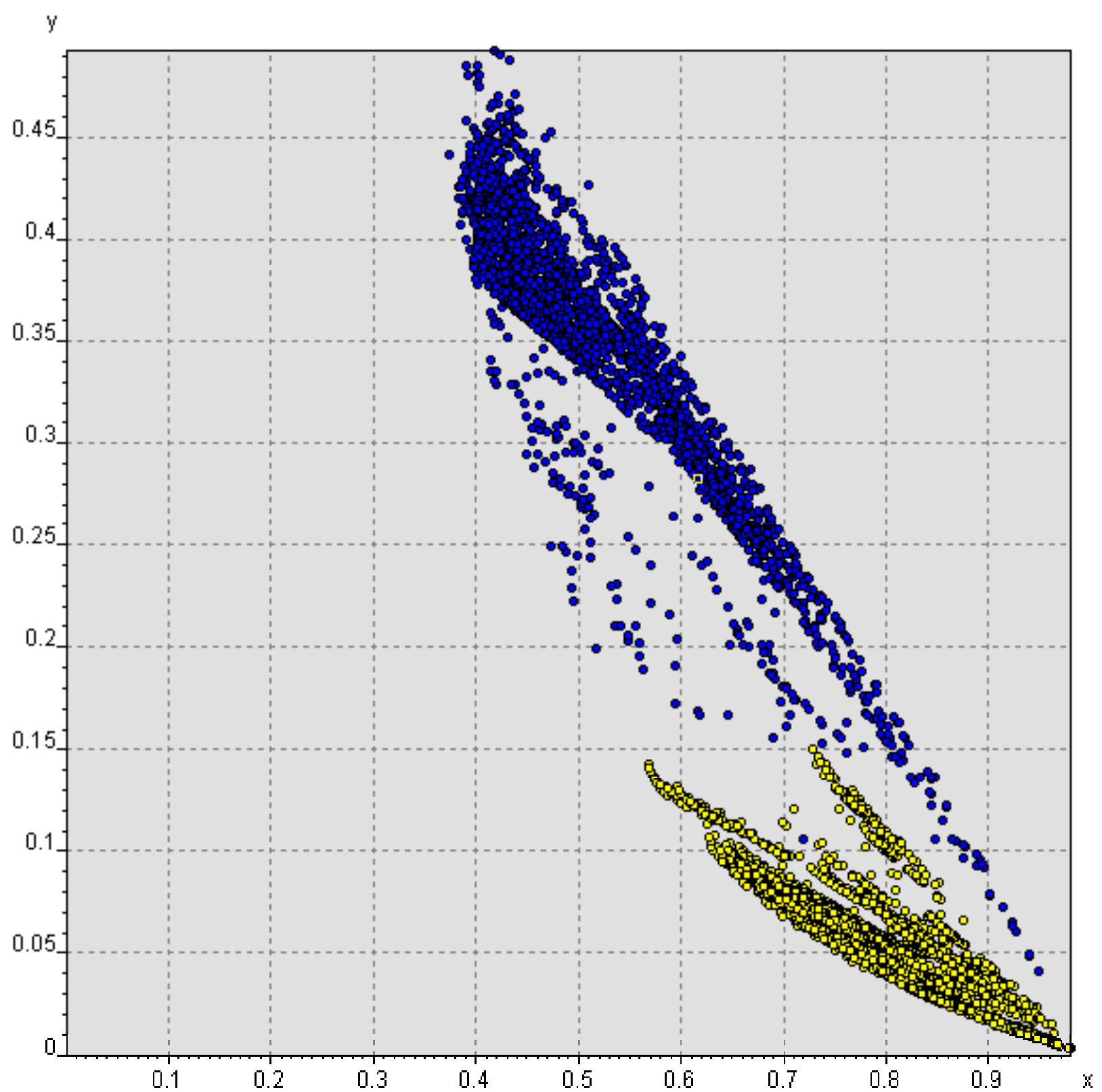

Fig. 16 Separation of 6913 quaternary systems into compound formers $(\bigcirc)$ and non-formers $(\bigcirc)$ based on a plot of the absolute difference (y-axis) $\left[3\left(\mathrm{RE}_{\mathrm{aME}}(\mathrm{A})-\mathrm{RE}_{\mathrm{aME}}(\mathrm{D})\right)+\left(\mathrm{RE}_{\mathrm{aME}}(\mathrm{B})-\mathrm{RE}_{\mathrm{aME}}(\mathrm{C})\right)\right] / 6\left(\mathrm{RE} \mathrm{aME}_{\mathrm{a}}\right.$ $(\mathrm{Ne})$ ) versus the ratio (X-axis) $\left[\mathrm{SZ}_{\mathrm{aME}}(\mathrm{A}) / \mathrm{SZ}_{\mathrm{aME}}(\mathrm{B})+\mathrm{SZ}_{\mathrm{aME}}(\mathrm{A}) / \mathrm{SZ}_{\mathrm{aME}}(\mathrm{C})+\mathrm{SZ}_{\mathrm{aME}}(\mathrm{A}) / \mathrm{SZ} \mathrm{aME}(\mathrm{D})+\right.$ $\mathrm{SZ}$ aME $\left.(\mathrm{B}) / \mathrm{SZ}_{\mathrm{aME}}(\mathrm{C})+\mathrm{SZ}_{\mathrm{aME}}(\mathrm{B}) / \mathrm{SZ}_{\mathrm{aME}}(\mathrm{D})+\mathrm{SZ}_{\mathrm{aME}}(\mathrm{C}) / \mathrm{SZ}_{\mathrm{aME}}(\mathrm{D})\right] / 6$. For the quaternary systems the absolute difference $=(|\mathrm{EP}(\mathrm{A})-\mathrm{EP}(\mathrm{B})|+|\mathrm{EP}(\mathrm{A})-\mathrm{EP}(\mathrm{C})|+|\mathrm{EP}(\mathrm{A})-\mathrm{EP}(\mathrm{D})|+|\mathrm{EP}(\mathrm{B})-\mathrm{EP}(\mathrm{C})|+\mid \mathrm{EP}$ (B) - EP (D) + + $\mathrm{EP}(\mathrm{C})-\mathrm{EP}(\mathrm{D}) \mid) /(\mathrm{n}(\mathrm{n}-1) / 2)$, with $\mathrm{EP}(\mathrm{A})<\mathrm{EP}(\mathrm{B})<\mathrm{EP}(\mathrm{C})<\mathrm{EP}(\mathrm{D})$ and $\mathrm{EP}(\mathrm{A}), \mathrm{EP}(\mathrm{B})$, $\mathrm{EP}(\mathrm{C}), \mathrm{EP}(\mathrm{D}) \leq 1$. EP $(\mathrm{A}), \mathrm{EP}(\mathrm{B}), \mathrm{EP}(\mathrm{C}), \mathrm{EP}(\mathrm{D})=$ elemental-property parameters of element A, B, C, and $\mathrm{D}$, respectively, and $\mathrm{n}=$ number of elements $=4$.

The hit rate as a function of $\mathrm{n}$ shows for the binary systems that the hit rates decreases by the same size in the intervals $\mathrm{n}=1-15$ and $\mathrm{n}=16-50$, therefore it is appropriate to give $95.6 \%(n=1) \rightarrow 75 \%(n=15)$. We even do not take into account that the binary systems data set is about one third of the ternary or quaternary data set. The clearest violation is the system $\mathrm{Li}-\mathrm{Sr}$, which contains five phases and is clearly located in the non-formers area. On the opposite side, the system Se-Te is clearly located in the former area, but several established, independently determined, phase diagrams show no binary phase. Here we dare to predict the existence of a binary phase, in analogy to the $\mathrm{S}-\mathrm{Se}$ system. Two additional violations in the non-forming area: $\mathrm{Hf}-\mathrm{V}$ and $\mathrm{V}-\mathrm{Zr}$ have one phase crystallizing in the prototype ${ }^{\mathrm{MgCu}}{ }_{2}$, 


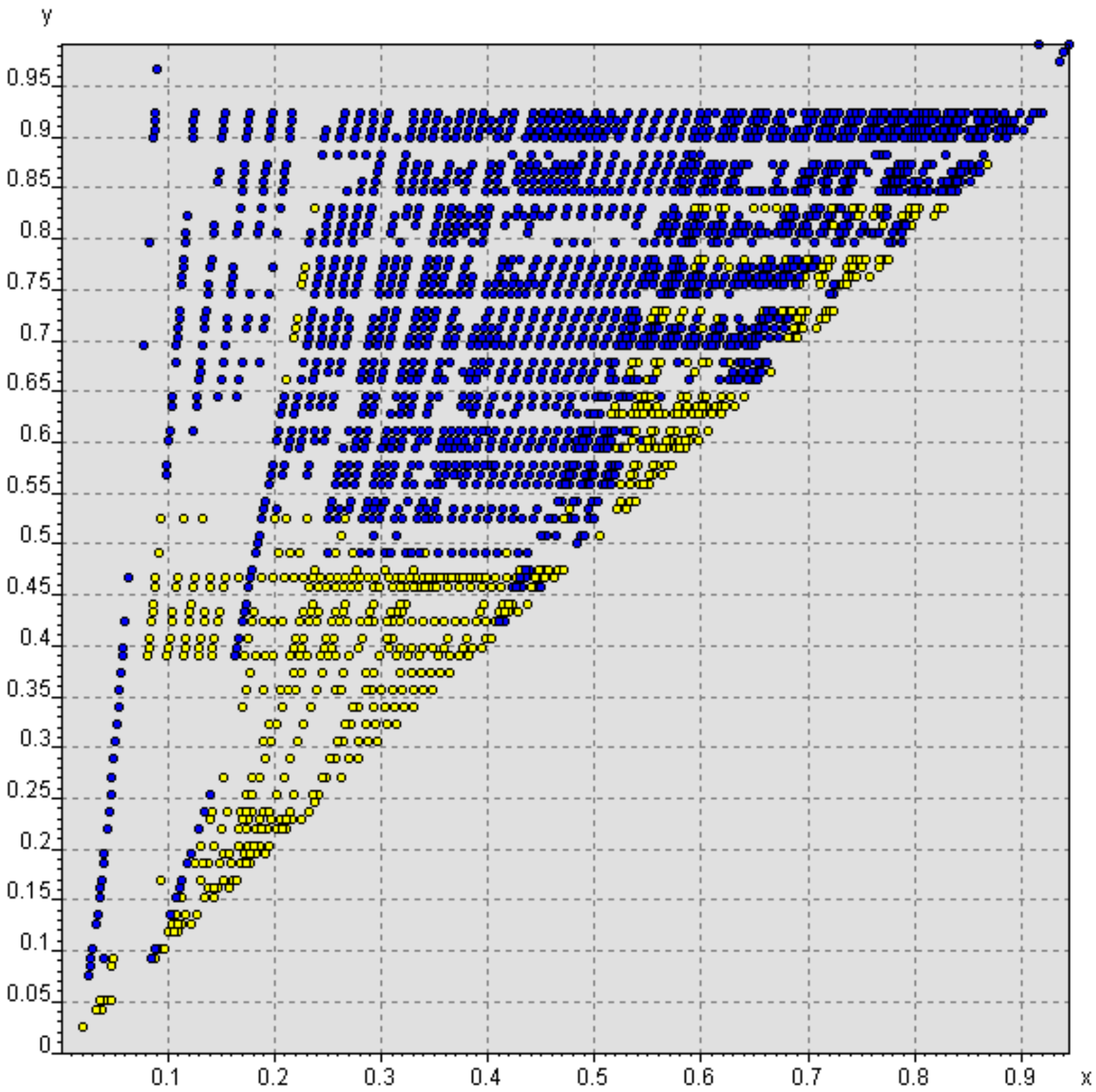

Fig. 17 Separation of 2318 binary systems into compound formers $(\mathbf{O})$ and non-formers $(\bigcirc)$ based on a plot of max. [(PN $\left.\left.\mathrm{PN}_{\mathrm{ME}}(\mathrm{A}) /\left(\mathrm{PN}_{\mathrm{ME}}\right)_{\max }, \mathrm{PN}_{\mathrm{ME}}(\mathrm{B}) /\left(\mathrm{PN}_{\mathrm{ME}}\right)_{\max }\right)\right]$ (y-axis) versus $\mathrm{PN}_{\mathrm{ME}}$ product $\left[\mathrm{PN}_{\mathrm{ME}}(\mathrm{A}) /\left(\mathrm{PN}_{\mathrm{ME}}\right)_{\max }\right.$ $\left.* \mathrm{PN}_{\mathrm{ME}}(\mathrm{B}) /\left(\mathrm{PN}_{\mathrm{ME}}\right)_{\max }\right]$ (x-axis) using Meyer's Periodic System.

cF24, 227' (Pauling File prototype notation [26,27]), which are very close to a 'binary' close-packed structure.

In Figs. 14-18 the most efficient operators seem to be difference and maximum. It is a peculiarity of ternary systems that for the feature max.(EP $(A, B, C))$, only the value of EP (A), of the chemical element A with the largest EP value is taken into account. The chemical elements $\mathrm{B}$ and $\mathrm{C}$ are irrelevant. For the difference: $\mid(\mathrm{EP}(\mathrm{A})-\mathrm{EP}(\mathrm{B})|+|(\mathrm{EP}(\mathrm{A})-\mathrm{EP}(\mathrm{C}) \mid+$ $|(\mathrm{EP}(\mathrm{B})-\mathrm{EP}(\mathrm{C}))|$ (equal to $\mathrm{EP}_{\max }(\mathrm{A}, \mathrm{B}, \mathrm{C})-\mathrm{EP}_{\text {min }}$ $(A, B, C)$ ) only the maximum and minimum values of EP are taken into account. The intermediate value EP appear to be irrelevant.

\section{Conclusions}

This work revealed the following new knowledge:

1) An adequate description of the derived elementalproperty parameters requires the introduction of the periodic number PN in addition to the well-established atomic number AN. AN and PN represent fundamental elemental-property parameters which are independent from each other.

2) The derived elemental-property parameters atomic size $\mathrm{SZ}_{\mathrm{a}}$, and its reciprocal, the atomic reactivity $\mathrm{RE}_{\mathrm{a}}$, can be expressed as functions of $\mathrm{AN}$ and PN. Other elemental-property parameter functions, like the mass density, can be described by combination of one or 


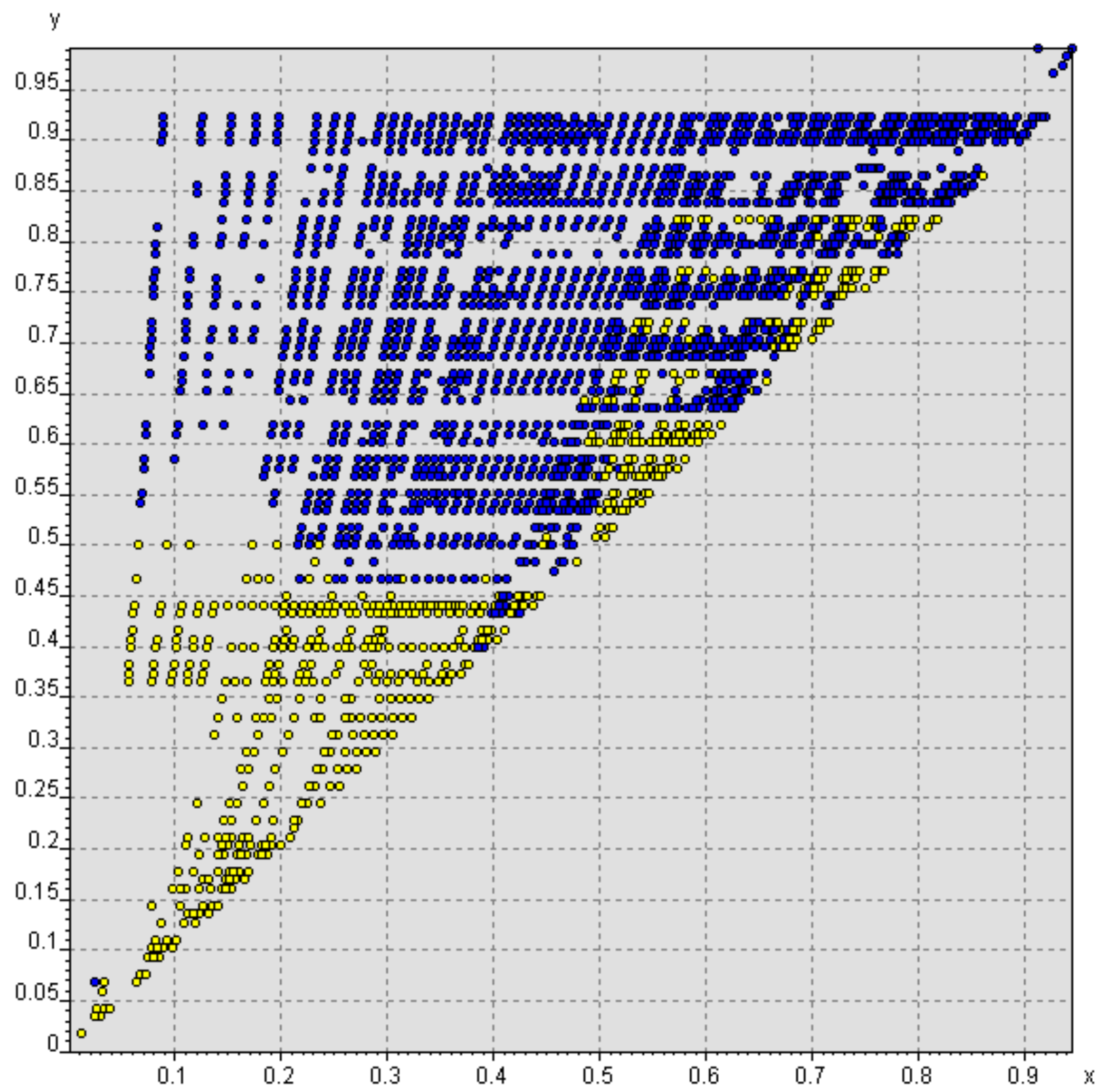

Fig. 18 Separation of 2318 binary systems into compound formers $(\mathbf{O})$ and non-formers $(\bigcirc)$ based on a plot of max. [(PN $\left.\mathrm{PND}_{\mathrm{MD}}(\mathrm{A}) /\left(\mathrm{PN}_{\mathrm{MD}}\right)_{\max }, \mathrm{PN}_{\mathrm{MD}}(\mathrm{B}) /\left(\mathrm{PN} \mathrm{MD}_{\max }\right)\right]\left(\mathrm{y}\right.$-axis) versus product $\left[\mathrm{PN} \mathrm{MD}_{\mathrm{M}}(\mathrm{A}) /\left(\mathrm{PN}_{\mathrm{MD}}\right)_{\max } *\right.$ $\left.\mathrm{PN}_{\mathrm{MD}}(\mathrm{B}) /\left(\mathrm{PN}_{\mathrm{MD}}\right)_{\max }\right]$ (X-axis), using Mendeleyev's Periodic System.

more patterns (for the mass density it is a combination of atomic number pattern and atomic size pattern).

3) The result of equation (2), the frequently used $\mathrm{RE}_{\mathrm{a}}=\mathrm{k}_{\mathrm{SZ}} \mathrm{k}_{\mathrm{RE}}\left(\mathrm{SZ}_{\mathrm{a}}\right)^{-1}$, is most outstanding. This means that the atomic reactivity (different electronegativity scales belong to this pattern group) of an element is the reciprocal value of its atomic size. This may be the reason why the 'electronegativity concept' was never really accepted in physics. Nevertheless in chemistry its ability to reflect the reactivity of the elements with each other is accepted and frequently used. To our knowledge the result that the atomic reactivity is simply the reciprocal of the corresponding atomic size is not found in the literature.

4) On the example of the problem of separating formers from non-formers in binary, ternary and quaternary systems, we verify and reformulate our previous postulate: "Structure-sensitive properties of materials are quantitatively described by the elemental-property parameters of the constituent chemical elements". The reformulation of the postulate results in: "Structure-sensitive material properties are quantitatively described by the elemental-property parameters AN and PN (or simple 
mathematical functions of them) of the constituent chemical elements". This generalization is an important step to strategically explore structuresensitive properties of materials.

5) It is worth mentioning some observations in context with the noble gases (= inert gases). It is known that noble gases create compounds only in very exceptional cases. Figs. 17 and 18 show that the systems containing noble gases are all located in the compound-forming area. The eight listed elementalproperty parameters belonging to the atomic reactivity patterns show only values for the absolute electronegativity $\mathrm{EN}(\mathrm{abs})$, and the first ionization potentials IE(first). They follow the general trend within GN 18, like our calculated atomic reactivity $\mathrm{RE}_{\mathrm{a}}$. Analogous observations are made for the elemental-property parameters $\operatorname{Rve}(\mathrm{S}), \operatorname{Rce}(\mathrm{S})$, and $\mathrm{R}(\mathrm{VD})$, belonging to the atomic size, which are also in general agreement with our calculated atomic size $\mathrm{SZ}_{\mathrm{a}}$. Looking at the binaries it appears that, from the about 500 noble-gas-containing systems, only 10 systems have been investigated. In these few investigated systems the following seven compounds are known: $\mathrm{XeO}_{3}, \operatorname{Ar}\left(\mathrm{H}_{2}\right)_{2}, \mathrm{KrF}_{2}, \mathrm{XeF}_{6}, \mathrm{XeF}_{4}, \mathrm{XeF}_{3}$, and $\mathrm{XeF}_{2}$. Obviously the conditions of existence for these noble-gas-containing compounds are quite different from those of the majority of the compounds considered in this work $(\mathrm{T}=298 \mathrm{~K}$ and atmospheric pressure). Nevertheless, the above-mentioned observations allow us to conclude that many more noble-gas-containing compounds can be expected.

\section{Acknowledgements}

The authors are grateful to Dr. F. Hulliger for his interest in the work and for his critical comments during the careful reading of the manuscript.

\section{References}

[1] G. Busch, H. Schade, in: Vorlesungen über Festkörperphysik, Birkhäuser, 1973.

[2] G.V. Samsonov, in: Handbook of the Physicochemical Properties of the Elements, IFI/Plenum Data Corporation, New York, 1968.

[3] J.C. Slater, in: Theory of Alloy Phases, American Society for Metals, Cleveland, OH, 1956.

[4] L. Meyer's Periodic Table, E.H. Sargent \& Co, 1964.

[5] D.I. Mendeleyev's Periodic Table, in: F.R. de Boer, R. Boom, W.C.M. Mattens, A.R. Miedema, A.K. Niessen, in: Cohesion in Metals, Vol. 1, F.R. de Boer, D.G. Pettifor (Eds.), NorthHolland, Amsterdam, 1988, p. 45.

[6] D.G. Pettifor, in: Intermetallic Compounds, Principles and Practice, Vol. 1, J.H. Westbrook, R.L. Fleischer (Eds.), Wiley, New York, 1994, pp. 419-438.
[7] A. Zunger, in: Structure and Bonding in Crystals, M. O'Keefe, A. Navrotsky (Eds.), Academic Press, New York, 1981, p. 73.

[8] E. Teatum, K. Gschneidner, J. Waber, LA-2345, U.S. Department of Commerce, Washington, DC, 1960.

[9] K. Schubert, private communication, 1990.

[10] F.R. de Boer, R. Boom, W.C.M. Mattens, A.R. Miedema, A.K. Niessen, in: Cohesion and Structure, Vol. 1, F.R. de Boer, D.G. Pettifor (Eds.), Elsevier Science Publishers B.V., Amsterdam, 1988, pp. 715-716.

[11] P. Villars, J.L.C. Daams, J. Alloys Compd. 197 (1993) 177-196.

[12] S.S. Batsanov, Sov. Sci. Rev. B. Chem. 15 (1990), 1-79.

[13] C. Kittel, Einführung in die Festkörperphysik, Oldenbourg Verlag, München, 1980, pp. 92-104.

[14] R.T. Sanderson, Inorganic Chemistry, Reinhold, New York, 1967, used in: G. Busch, H. Schade, Vorlesungen über Festkörperphysik, Birkhäuser, 1973.

[15] D.G. Pettifor, J. Solid State Commun. 51 (1984) 31.

[16] P. Villars, Dissertation Nr. 6787, ETH, Zürich, Switzerland, 1981.

[17] P. Villars, K. Brandenburg, M. Berndt, S. LeClair, A. Jackson, Y.-H. Pao, B. Igelnik, M. Oxley, B. Bakshi, P. Chen, S. Iwata, J. Alloys Compd. 317-318 (2001) 26-38.

[18] P. Villars, K. Cenzual, J. Daams, Y. Chen, S. Iwata, J. Alloys Compd. 367 (2004) 167-175.

[19] P. Villars, in: Intermetallic Compounds, Principles and Practice, Vol. 1, J.H. Westbrook, R.L. Fleischer (Eds.), Wiley, New York, 1994, pp. 227-275.

[20] J.L.C. Daams, in: Intermetallic Compounds, Principles and Practice, Vol. 1, J.H. Westbrook, R.L. Fleischer (Eds.), Wiley, New York, 1994, pp. 363-383.

[21] ICSD, FIZ/NIST, Fachinformations Zentrum Karlsruhe, Germany, 1999.

[22] P. Villars, L.D. Calvert, Pearson's Handbook of Crystallographic Data for Intermetallic Phases, $2^{\text {nd }}$ Ed., Vols. 1-4, ASM International, Materials Park, OH, 1991.

[23] P. Villars, Pearson's Desk Edition, Vols. 1-2, ASM International, Materials Park, OH, 1997.

[24] T.B. Massalski, H. Okamoto, Binary Alloy Phase Diagrams, $2^{\text {nd }}$ Ed., ASM International, Materials Park, OH, 1994, and on CD-ROM, 1998.

[25] P. Villars, A. Prince, H. Okamoto, Handbook of Ternary Alloy Phase Diagrams, Vols. 1-10, ASM International, Materials Park, OH, 1994, and on CD-ROM, 1996.

[26] P. Villars, K. Cenzual, J. Daams, F. Hulliger, T. Massalski, H. Okamoto, K. Osaki, A. Prince, Pauling File, Binaries Edition, on CD-ROM, ASM International, Materials Park, OH, 2002. 
P. Villars et al., A new approach to describe elemental-property parameters

[27] P. Villars, K. Cenzual, H. Okamoto, J. Daams, K. Osaki, A. Prince, "Pauling File $(L P F)$ ", Multinaries Edition (in preparation).
[28] K. Brandenburg, M. Berndt, P. Villars, "DISCOVERY", Crystal Impact, Bonn, Germany, 2000.

Proceeding of the IX International Conference on Crystal Chemistry of Intermetallic Compounds, Lviv, September 20-24, 2005. 